\title{
Análise de 1071 reoperações para revascularização do miocárdio: resultados obtidos e conduta sugerida com base nessa experiência
}

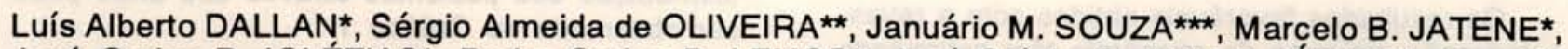
José Carlos R. IGLÉZIAS*, Pedro Carlos P. LEMOS*, José Otávio C. AULER JÚNIOR*, Geraldo VERGINELLI*, Fúlvio PILEGGI*, Adib D. JATENE*

DALLAN, L. A.; OLIVEIRA, S. A.; SOUZA, J. M.; JATENE, M. B.; IGLÉZIAS, J. C. R.; LEMOS, P. C. P.; AULER JÚNIOR, J. O. C.; VERGINELLI, G.; PILEGGI, F.; JATENE, A. D. - Análise de 1071 reoperaçōes para revascularização do miocárdio; resultados obtidos e conduta sugerida com base nessa experiência. Rev. Bras. Cir. Cardiovasc. 7(2):61-77, 1992.

RESUMO: Entre janeiro de 1979 e janeiro de 1992, foram realizadas 1071 reoperaçōes para revascularizaçāo do miocárdio, no Instituto do Coraçāo e em um de seus Serviços afiliados (Hospital da Beneficência Portuguesa - São Paulo). Destas, 1015 consistiam na primeira reoperação, 53 na segunda e 3 na terceira. A reoperaçāo foi motivada por progressāo da aterosclerose coronária em $117(10,9 \%)$ casos, oclusão parcial ou total dos enxertos em $183(17,1 \%)$, sua associaçāo em $728(67,9 \%)$, por problemas técnicos em $21(1,9 \%)$ e por outras causas em $22(2,1 \%)$. A idade dos pacientes variou de 34 a 84 anos $(M=61,6)$, com predomínio do sexo masculino $(86,1 \%)$ e da raça branca $(96,5 \%)$. O período entre a primeira e a segunda operaçāo variou do mesmo dia a 22 anos $(M=9,3)$. Entre a segunda e a terceira, esse período variou de 1 a 11 anos $(M=8,0)$ e entre a terceira e a quarta variou de 7 a 9 anos $(M=7,7)$. Na reoperação, utilizou-se enxerto de uma das artérias mamárias em $610(56,9 \%)$ casos, ambas artérias mamárias em $192(17,9 \%)$, artéria gastroepiplóica em $6(0,6 \%)$ e artéria epigástrica em $5(0,5 \%)$. No total, em $813(75,9 \%)$, das 1071 reoperaçōes, empregou-se ao menos um enxerto arterial na revascularizaçāo do miocárdio. Foram observados $87(8,1 \%)$ óbitos hospitalares nesse período, dos quais $39(44,8 \%)$ diretamente relacionados à disfunçāo ventricular e $48(55,2 \%)$ decorrentes de outras complicaçōes: pulmonares (22), sepsis (8), distúrbios da coagulaçāo (7), neurológicas (6), isquemia mesentérica (5). Diversos fatores foram associados à maior mortalidade, dentre os quais destacamos: 1) fatores de risco pré-operatórios (diabetes, hipertensāo, hipercolesterolemia, obesidade, tabagismo, familiar etc.): 731 apresentavam até dois fatores de risco, com $35(4,8 \%)$ óbitos; 299 tinham três ou quatro desses fatores de risco, com $38(12,7 \%)$ óbitos e em 4 havia cinco ou mais fatores de risco, com 14 $(34,1 \%)$ óbitos; 2) classe funcional (CF) pré-operatória: 317 encontravam-se em CF I ou II, dos quais 7 $(2,2 \%)$ faleceram; 449 em CF III, com 34 (7,6\%) óbitos e 305 em CF IV, com 46 (15,1\%) óbitos; 3$)$ comprometimento triarterial associado ou não a lesão de tronco: 788 apresentavam tal tipo de comprometimento arterial, dos quais $74(9,4 \%)$ faleceram. Dentre 283 com lesão uni ou biarterial, $13(4,6 \%)$ foram a óbito; 4) caráter de emergência da cirurgia: dentre 110 operaçōes de emergência, foram observados $35(31,8 \%)$ óbitos. Dentre 961 cirurgias eletivas, houve $52(5,4 \%)$ óbitos. Nos últimos dois anos, entretanto, foram realizadas 379 re-revascularizaçōes do miocárdio, tendo sido observados apenas 13 $(3,4 \%)$ óbitos. Esse decréscimo de mortalidade em relação aos anos anteriores foi atribuído, entre outros

Trabalho realizado no Instituto do Coração do Hospital das Clínicas da Faculdade de Medicina da Universidade de São Paulo e no Hospital da Beneficência Portuguesa, Sáo Paulo, SP, Brasil.

Apresentado ao $19^{\circ}$ Congresso Nacional de Cirurgia Cardíaca. Sáo Paulo, SP, 7 a 9 de maio, 1992

Laureado com o "Prêmio Nacional de Cirurgia Cardíaca - 1992".

* Do Instituto do Coração do Hospital das Clínicas da Faculdade de Medicina da Universidade de Sáo Paulo.

* Do Instituto do Coraçáo e do Hospital da Beneficência Portuguesa.

** Do Hospital da Beneficência Portuguesa.

Endereço para separatas: Luís Alberto Dallan. Av. Dr. Enéas Carvalho de Aguiar, 44. Divisão Cirúrgica. 05403 São Paulo, SP, Brasil. 
DALLAN, L. A.; OLIVEIRA, S. A.; SOUZA, J. M.; JATENE, M. B.; IGLÉZIAS, J. C. R.; LEMOS, P. C. P.; AULER JÚNIOR, J. O. C.; VERGINELLI, G.; PILEGGI, F.; JATENE, A. D. - Análise de 1071 reoperaçōes para revascularizaçāo do miocárdio: resultados obtidos e conduta sugerida com base nessa experiência. Rev. Bras. Cir. Cardiovasc. 7(2):61-77, 1992.

\begin{abstract}
fatores, aos métodos de proteçāo miocárdica empregados, especialmente nos doentes com pior funçāo ventricular. Nesses dois anos foi também dado especial destaque ao emprego de enxertos arteriais na re-revascularizaçāo do miocárdio. A média da utilizaçāo de ao menos um enxerto arterial na reoperaçāo coronária elevou para $82,2 \%$ (259/315). Acreditamos que, através da abordagem cirúrgica adequada, da utilizaçāo crescente de enxertos arteriais e, especialmente, pela indicação cirúrgica precoce, permitindo a re-revascularizaçāo de forma eletiva e, ainda, com boa viabilidade miocárdica, os resultados futuros serāo mais promissores.
\end{abstract}

DESCRITORES: miocárdio, revascularizaçāo, reoperaçāo.

\section{INTRODUÇĀO}

Os resultados favoráveis obtidos com a revascularizaçāo cirúrgica do miocárdio têm estimulado um número crescente de operaçōes, especialmente nas últimas duas décadas. A simplificação da tática cirúrgica, associada à baixa mortalidade e à real melhora na qualidade de vida do paciente anginoso, justifica esse fato.

Entretanto, a aterosclerose coronária é uma doença progressiva e pode acometer nāo apenas artérias isentas de lesōes obstrutivas, por ocasiāo da primeira operaçāo, como também os enxertos empregados na revascularização do miocárdio.

Recentes estudos têm demonstrado que, apesar de riscos superiores à primeira revascularizaçāo cirúrgica, as reoperaçōes sāo factíveis na maioria dos pacientes e vêm apresentando complicaçōes pós-operatórias, e mortalidade progressivamente menores ${ }^{19,21,25}$, justificando a sua realizaçāo.

\section{CASUÍSTICA, MÉTODOS E RESULTADOS}

Foram estudados 1071 pacientes consecutivos submetidos a nova cirurgia para revascularizaçăo do miocárdio, no Instituto ço Coração e em um de seus Serviços afiliados (Hospital da Beneficência Portuguesa de Sāo Paulo).

\section{GRÁFICO 1}

\section{DISTRIBUICĀO DAS REOPERACÓES POR ANO}

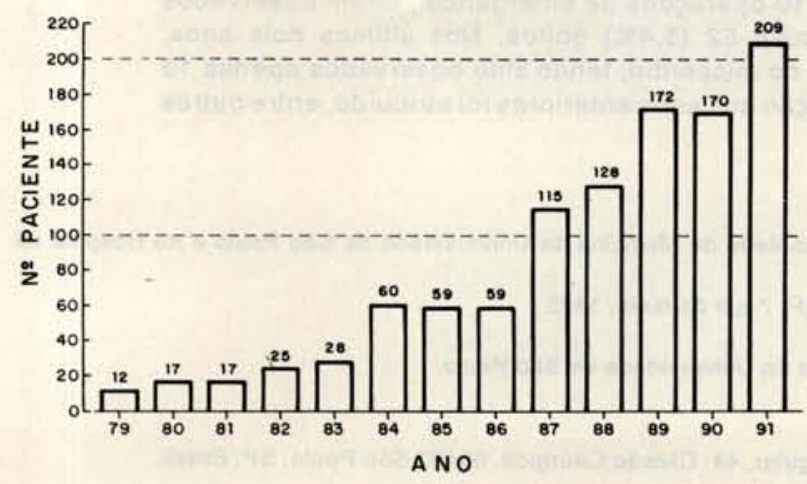

O período variou de janeiro/79 a janeiro/92 e a distribuição dos pacientes através dos anos pode ser observada no Gráfico 1.

Dentre os pacientes estudados, 1015 foram reoperados pela primeira vez, 53 pela segunda e três pela terceira. A maioria dos pacientes era do sexo masculino $(86,1 \%)$ e da raça branca $(96,5 \%)$.

A principal indicaçāo para a reoperação coronária foi a associaçāo da progressāo da doença nas artérias nativas, com a oclusāo parcial ou total dos enxertos (67,9\%). A progressāo isolada da doença coronária foi a responsável por $10,9 \%$ das reoperaçōes e a oclusāo parcial ou total dos enxertos isoladamente motivou $17,1 \%$ das reoperaçōes. As indicaçōes restantes $(4,1 \%)$ decorreram de problemas técnicos com os enxertos $(2,0 \%)$, oclusāo de artéria subclávia $(0,2 \%)$ e outras associaçōes $(1,9 \%)$ (Tabela 1).

Os períodos decorridos entre as reoperaçōes, com as respectivas mortalidades, podem ser observados na Tabela 2 .

Foi determinado o número de fatores de risco coronário por paciente no pré-operatório (HAS, tabagismo, diabetes, familiar, obesidade etc.) e correlacionado à mortalidade cirúrgica. Em 63 pacientes nāo se detectou nenhum desses fatores, dos quais $1(1,6 \%)$ veio a falecer. Em 301 pacientes havia 1 fator de risco, com $9(3,0 \%)$ óbitos. Dentre 367 pacientes com 2 fatores de risco, $25(6,8 \%)$ faleceram. Em 205 pacientes foram detectados ao

TABELA 1 INDICAÇĀO DA REOPERAÇĀO

\begin{tabular}{|c|c|c|}
\hline Indicação & $\mathrm{N}^{0} \mathrm{Pz}$ & acientes \\
\hline Progressão da doença coronária (isolada) & 117 & $(10,9 \%)$ \\
\hline $\begin{array}{l}\text { Oclusão parcial ou total dos } \\
\text { enxertos (isolada) }\end{array}$ & 183 & $(17,1 \%)$ \\
\hline Ambos & 728 & $(67,9 \%)$ \\
\hline $\begin{array}{l}\text { Problemas técnicos na realização } \\
\text { dos enxertos }\end{array}$ & 21 & $(2,0 \%)$ \\
\hline Oclusāo de artéria subclávia & 2 & $(0,2 \%)$ \\
\hline Outras associaçōes & 20 & $(1,9 \%)$ \\
\hline
\end{tabular}


DALLAN, L. A.; OLIVEIRA, S. A.; SOUZA, J. M.; JATENE, M. B.; IGLÉZIAS, J. C. R.; LEMOS, P. C. P.; AULER JÚNIOR, J. O. C.; VERGINELLI, G.; PILEGGI, F.; JATENE, A. D. - Análise de 1071 reoperaçōes para revascularização do miocárdio: resultados obtidos e conduta sugerida com base nessa experiência. Rev. Bras. Cir. Cardiovasc. 7(2):61-77, 1992.

TABELA 2

PERIODOS DECORRIDOS ENTRE AS REOPERAÇÕES, COM AS RESPECTIVAS MORTALIDADES.

\section{PERÍODO ENTRE $1^{\circ}$ E A 2: REVASCULARIZAÇĀO DO MIOCÁRDIO}

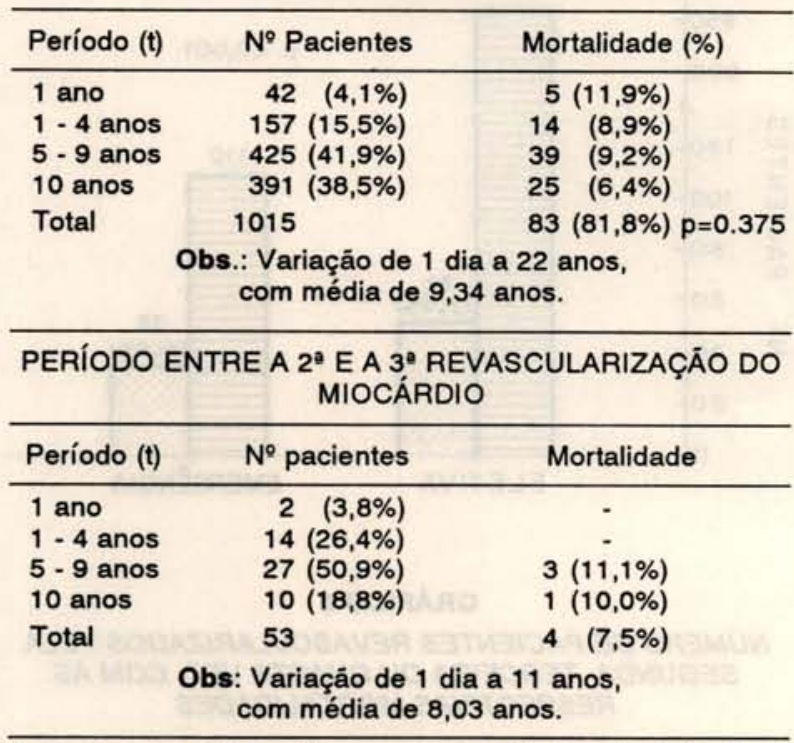

Período entre a $3^{\circ}$ e a $4^{\circ}$ revascularização do miocárdio: 7 a 9 anos (média $=7,66$ anos) $=3$ pacientes -0 óbitos.

menos três fatores de risco, com $19(9,3 \%)$ óbitos. Quatro desses fatores foram observados em 94 pacientes, com $19(20,2 \%)$ óbitos; 41 pacientes apresentavam 5 ou mais fatores de risco, dos quais $14(34,1 \%)$ faleceram.

Ao agruparmos esses dados, observamos que, em 731 pacientes com até 2 fatores de risco pré-
GRÁFICO 2

RELAÇĀO DA CLASSE FUNCIONAL (CF) E DA FRAÇĀO DE EJECCAOO (FE) PRÉ-OPERATORIAS, COMAS PERSPECTIVAS MORTALIDADES OPERATÓRIAS

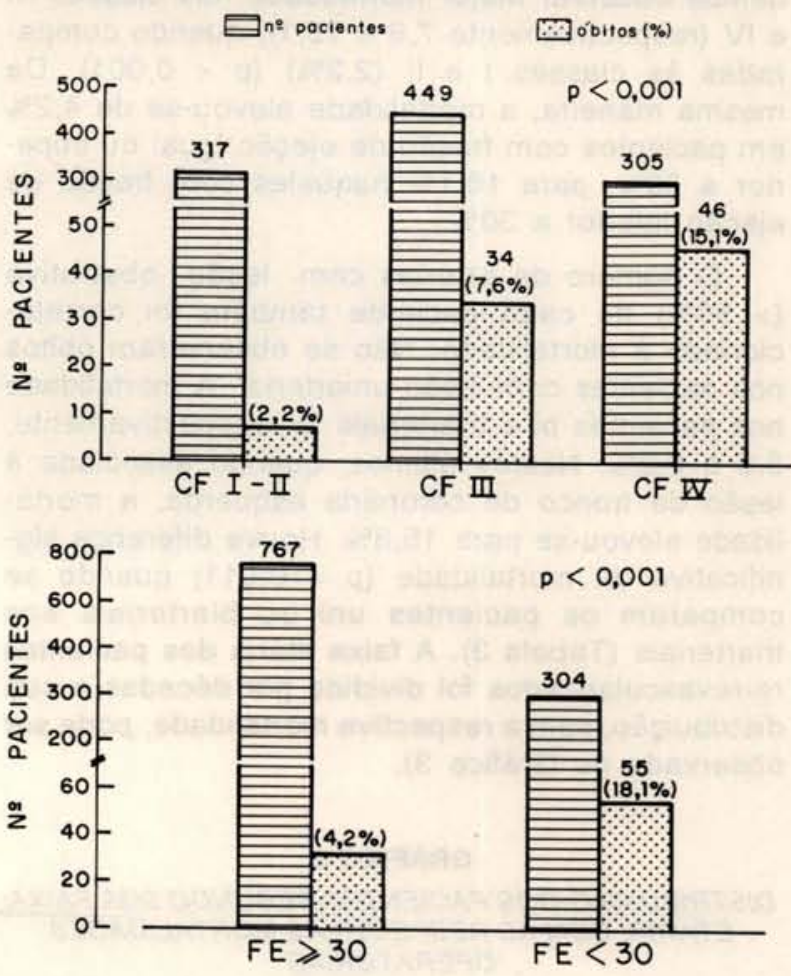

operatório, a mortalidade cirúrgica foi de $4,8 \%$. Dentre 299 pacientes com 3 e 4 desses fatores, a mortalidade elevou-se para $12,7 \%$; e na presença de 5 ou mais fatores ( 41 pacientes), a mortalidade atingiu $34,1 \%)$.

TABELA 3

ARTÉRIAS CORONÁRIAS COM OBSTRUÇĀO (

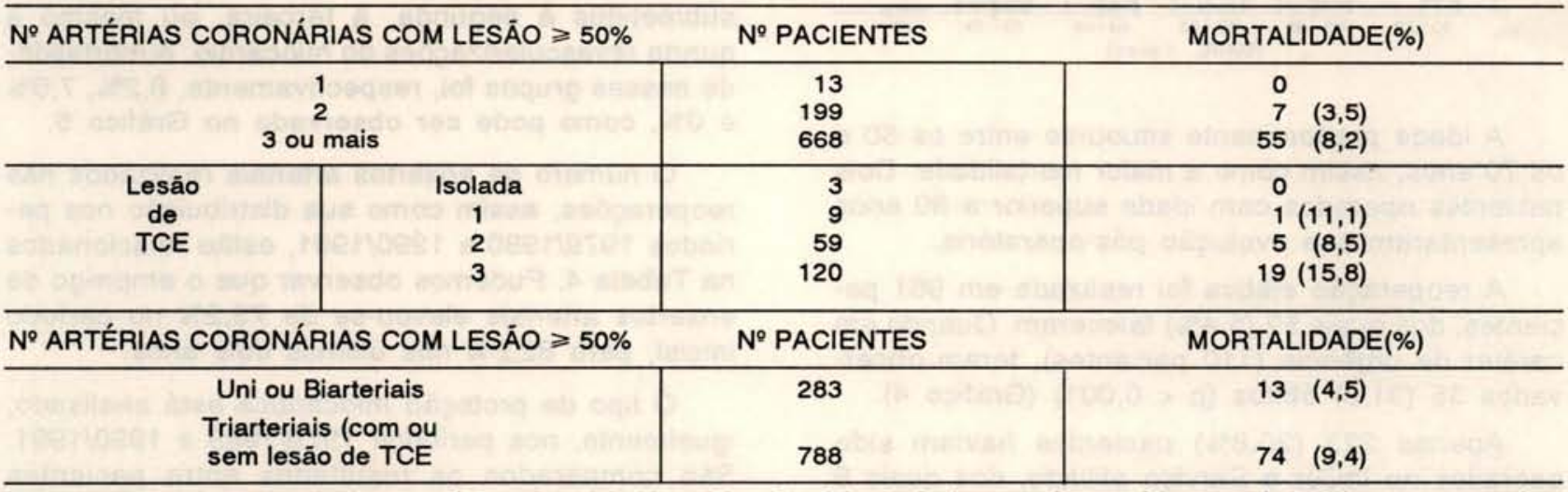

Acima $=n^{9}$ de pacientes com lesỏes coronárias uniarteriais, biarteriais, triarteriais e lesão de tronco de coronária esquerda (TCE), com as respectivas mortalidades operatórias.

Abaixo = comparação da mortalidade operatória entre pacientes com lesão coronária uni ou biarterial, com pacientes portadores de 3 ou mais artérias lesadas. 
DALLAN, L. A.; OLIVEIRA, S. A.; SOUZA, J. M.; JATENE, M. B.; IGLÉZIAS, J. C. R.; LEMOS, P. C. P.; AULER JÚNIOR, J. O. C.; VERGINELLI, G.; PILEGGI, F.; JATENE, A. D. - Análise de 1071 reoperaçōes para revascularizaçāo do miocárdio: resultados obtidos e conduta sugerida com base nessa experiência. Rev. Bras. Cir. Cardiovasc. 7(2):61-77, 1992.

A classe funcional (NYHA) e a fraçāo de ejeçāo pré-operatória dos pacientes, com as respectivas mortalidades, estão discriminadas no Gráfico 2. Pudemos observar maior mortalidade nas classes III e IV (respectivamente 7,6 e 15,1), quando comparadas às classes I e II $(2,2 \%)(p<0,001)$. Da mesma maneira, a mortalidade elevou-se de $4,2 \%$ em pacientes com fração de ejeção igual ou superior a $30 \%$, para $18,1 \%$ naqueles com fração de ejeção inferior a $30 \%$.

O número de artérias com lesão obstrutiva (>50\%) de cada paciente também foi correlacionado à mortalidade. Não se observaram óbitos nos pacientes com lesão uniarterial. A mortalidade nos pacientes bi e triarteriais foi, respectivamente, 3,5 e $8,2 \%$. Nestes últimos, quando associada à lesão de tronco de coronária esquerda, a mortalidade elevou-se para $15,8 \%$. Houve diferença significativa da mortalidade ( $p=0,011)$ quando se comparam os pacientes uni ou biarteriais aos triarteriais (Tabela 3). A faixa etária dos pacientes re-revascularizados foi dividida por décadas e sua distribuiçāo, com a respectiva mortalidade, pode ser observada no Gráfico 3).

\section{GRÁFICO 3}

DISTRIBUICAĀO DOS PACIENTES SEGUNDO SUA FAIXA ETARIA, COM AS RESPECTIVAS MORTALIDADES OPERATORIAS

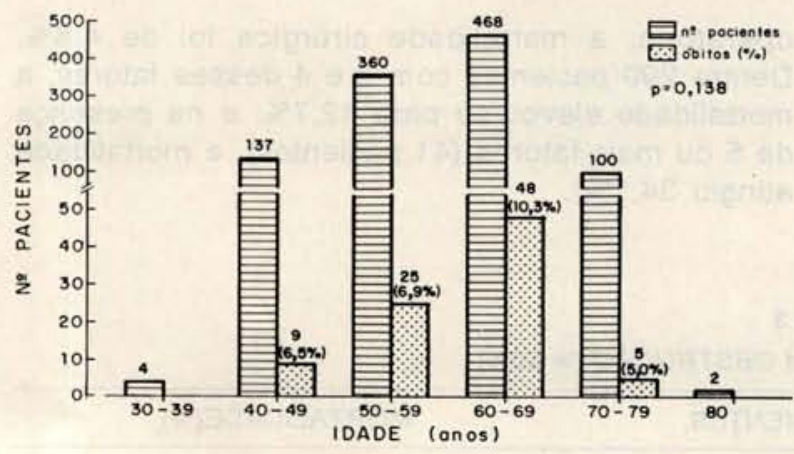

A idade predominante situou-se entre os 50 e os 70 anos, assim como a maior mortalidade. Dois pacientes operados com idade superior a 80 anos apresentaram boa evolução pós-operatória.

A reoperaçăo eletiva foi realizada em 961 pacientes, dos quais $52(5,4 \%)$ faleceram. Quando em caráter de urgência (110 pacientes), foram observados $35(31,8)$ óbitos $(\mathrm{p}<0,001)$ (Gráfico 4$)$.

Apenas $223(20,8 \%)$ pacientes haviam sido operados no InCór e Serviço afiliado, dos quais 9 $(4,03 \%)$ faleceram. Dentre os $848(79,2 \%)$ pacientes oriundos de outras Instituiçōes, $78(9,2 \%)$ foram a óbito $(p=0,012)$.
GRÁFICO 4

CARATER DA REOPERAÇÄO COM A RESPECTIVA MORTALIDADE

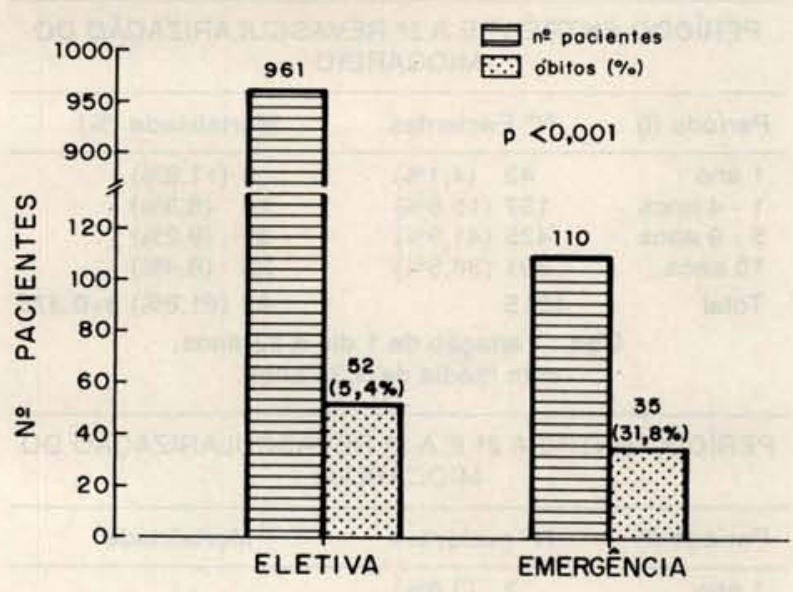

GRÁFICO 5

NÚMERO DE PACIENTES REVASCULARIZADOS PELA SEGUNDA, TERCEIRA OU QUARTA VEZ, COM AS RESPECTIVAS MORTALIDADES

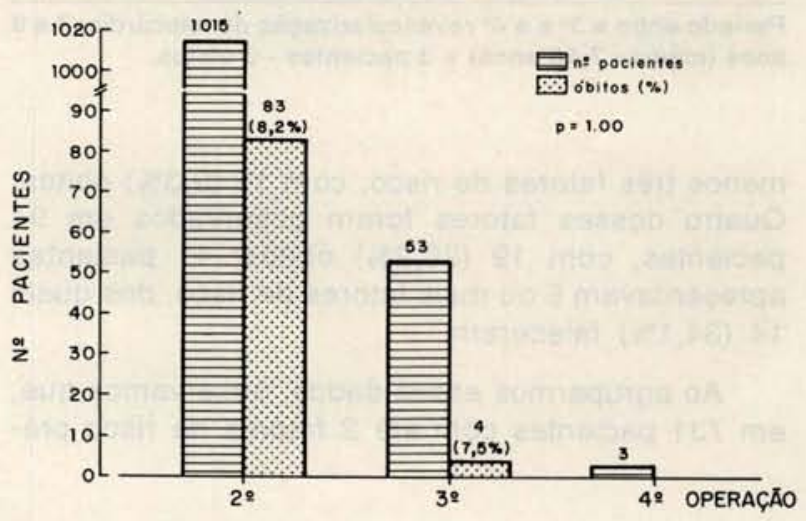

Em nossa casuística, observamos pacientes submetidos à segunda, à terceira, ou mesmo à quarta revascularizaçōes do miocárdio. A mortalidade nesses grupos foi, respectivamente, $8,2 \%, 7,5 \%$ e $0 \%$, como pode ser observado no Gráfico 5 .

O número de enxertos arteriais realizados nas reoperaçōes, assim como sua distribuição nos períodos 1979/1980 e 1990/1991, estão relacionados na Tabela 4. Pudemos observar que o emprego de enxertos arteriais elevou-se de $73,2 \%$ no período inicial, para $82,2 \%$ nos últimos dois anos.

O tipo de proteção miocárdica está analisado, igualmente, nos períodos 1979/1989 e 1990/1991. São comparados os resultados entre pacientes operados com cardioplegia e com pinçamento aórtico intermitente (Gráfico 6). Observamos tendência de emprego crescente de solução cardioplégica em 
DALLAN, L. A.; OLIVEIRA, S. A.; SOUZA, J. M.; JATENE, M. B.; IGLÉZIAS, J. C. R.; LEMOS, P. C. P.; AULER JÚNIOR, J. O. C.; VERGINELLI, G.; PILEGGI, F.; JATENE, A. D. - Análise de 1071 reoperaçōes para revascularizaçāo do miocárdio: resultados obtidos e conduta sugerida com base nessa experiência. Rev. Bras. Cir. Cardiovasc. 7(2):61-77, 1992.

TABELA 4

TIPOS DE ENXERTOS ARTERIAIS EMPREGADOS E SUA DISTRIBUIÇĀOO EM PERIOODOS DIVERSOS DAS REOPERAÇŌES.

TIPOS DE ENXERTOS ARTERIAIS UTILIZADOS NAS REOPERAÇÖES

\begin{tabular}{lrrr}
\hline Enxertos & \multicolumn{3}{c}{ Ne pacientes $^{\circ}$} \\
\hline 1 art. mamária & 610 & $(56,9 \%)$ \\
2 arts mamárias & 192 & $(17,9 \%)$ \\
Art. gastroepliploica D & 6 & $(0,6 \%)$ \\
Art. Epigástrica & 5 & $(0,5 \%)$ \\
TOTAL & 813 & $(75,9 \%)$ \\
\hline NÚMERO DE ENXERTOS ARTERIAIS POR PERIODO \\
\hline Período No pacientes operados & $N^{\circ}$ pacientes com \\
\multicolumn{3}{l}{ enxertos arteriais (\%) } \\
\hline 1979 a 1989 & 756 & 554 & $(73,2 \%)$ \\
1990 a 1991 & 315 & 259 & $(82,2 \%)$ \\
TOTAL & 1071 & 813 & $(75,9 \%)$ \\
\hline
\end{tabular}

\section{GRÁFICO 6}

DISTRIBUIÇĀO DO NÚMERO DE PACIENTES E RESPECTIVA MORTALIDADE QUANTO Á PROTEÇĀO MIOCÁRDICA: CARDIOPLEGIA, PINÇAMENTO AORTICO INTERMITENTE OU OPERADOS SEM CIRCULAÇĀO EXTRACORPOREA (CEC). ACIMA: PERIODOO DE 1979 A 1989; ABAIXO: PERIOODO DE 1990 A 1991

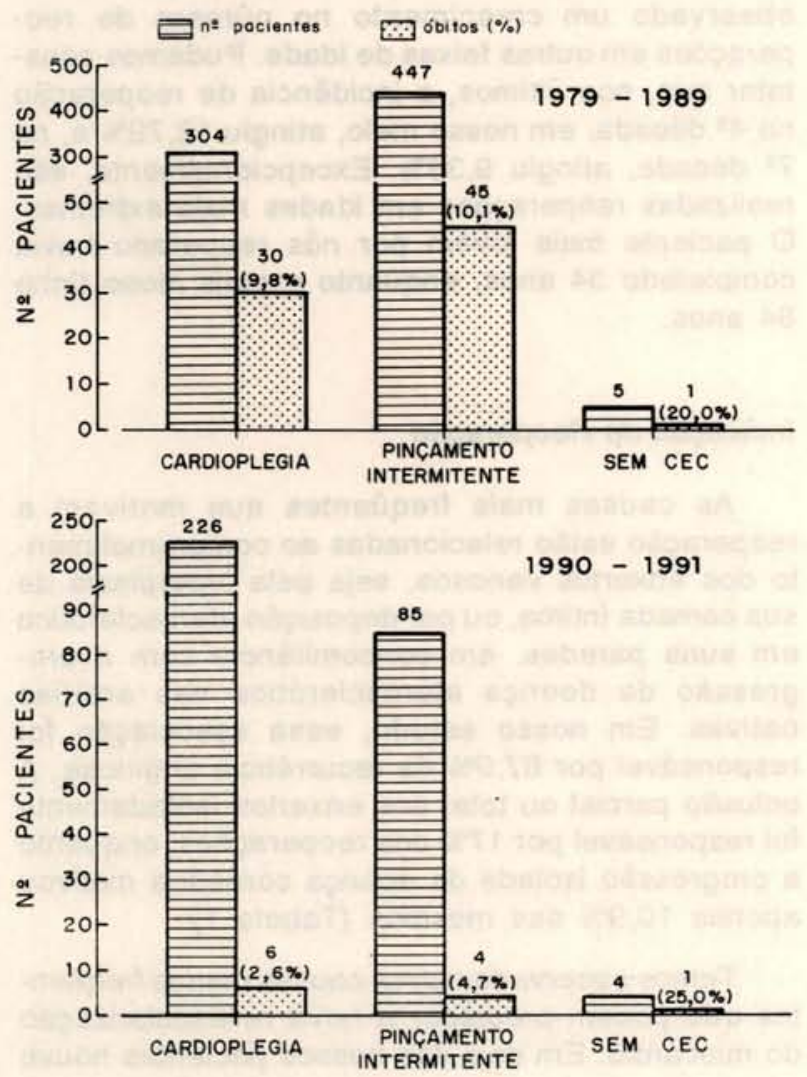

reoperaçōes nos últimos anos. Houve aparente reduçāo na mortalidade com êsse método, embora sem significado estatístico $(p=0,470)$.

Dentre as complicaçōes intra e pós-operatórias, destacamos, em ordem decrescente: infecção em ferida torácica ou em membros inferiores em 102 $(9,5 \%)$ dos pacientes, sendo 8 mediastinites. Infarto agudo do miocárdio (IAM) ocorreu em $95(8,1 \%)$ pacientes. Observamos insuficiência respiratória em $73(7,8 \%)$ pacientes. Cinqüenta e três $(4,9 \%)$ pacientes necessitaram revisāo de hemostasia por sangramento excessivo no pós-operatório. Cinqüenta e um $(4,8 \%)$ pacientes apresentaram complicaçōes renais, $29(2,7 \%)$ complicaçōes abdominais, 28 $(2,6 \%)$ neurológicas e $19(1,8 \%)$ vasculares periféricas.

Observamos $18(1,7 \%)$ complicaçōes durante a esternotomia. Dentre elas, constatamos laceração de ventrículo direito (VD) em 8 pacientes, de ventrículo esquerdo (VE) em 3 , de veia inominada em 3 , de átrio direito em 2 , de pulmão e de aorta em 1 paciente.

Ocorreram $87(8,1 \%)$ óbitos dentre os 1071 pacientes, sendo $39(44,8 \%)$ decorrentes de disfunção ventricular e $48(55,2 \%)$ de causas não miocárdicas. Dentre elas, observamos, em ordem decrescente, as complicaçōes pulmonares (22 pacientes), sepsis (8 pacientes), distúrbios de coagulação (7 pacientes), complicaçōes neurológicas (6 pacientes) e isquemia mesentérica (5 pacientes).

\section{GRÁFICO 7}

NÚMERO DE PACIENTES OPERADOS NOS PERIODOS 1979-1989 E 1990-1991. OBSERVA-SE QUEDA SIGNIFICATIVA DA MORTALIDADE NESSES PERIODOS (10,7\% PARA 3,4\%)

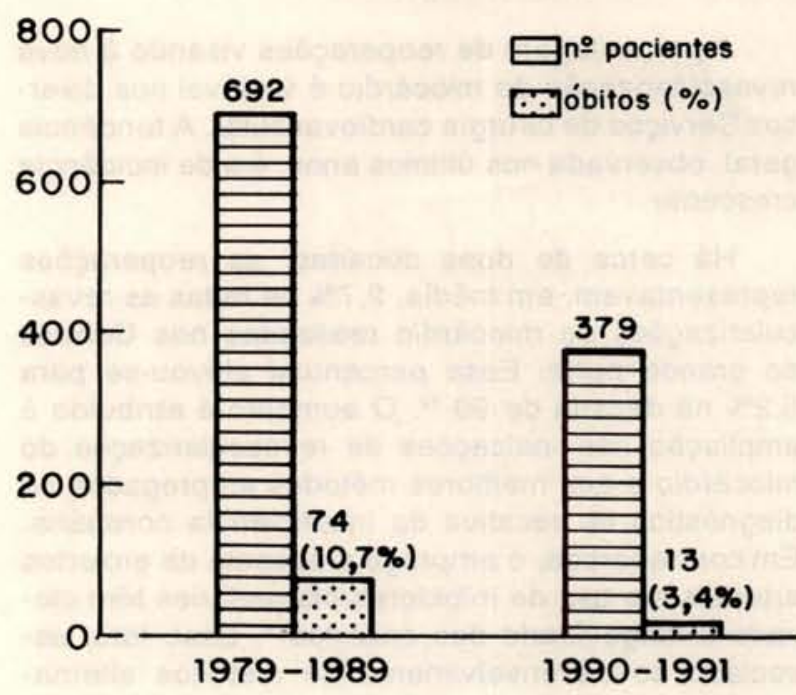


DALLAN, L. A.; OLIVEIRA, S. A.; SOUZA, J. M.; JATENE, M. B.; IGLÉZIAS, J. C. R.; LEMOS, P. C. P.; AULER JÚNIOR, J. O. C.; VERGINELLI, G.; PILEGGI, F.; JATENE, A. D. - Análise de 1071 reoperaçōes para revascularizaçāo do miocárdio: resultados obtidos e conduta sugerida com base nessa experiência. Rev. Bras. Cir. Cardiovasc. 7(2):61-77, 1992.

A mortalidade cirúrgico-hospitalar decresceu significaticamente nos últimos 2 anos. No período de 1979 a 1989 , foram operados 692 pacientes, dos quais $74(10,7 \%)$ faleceram. Nos anos 1990 e 1991 , dentre 379 pacientes operados, apenas $13(3,4 \%)$ morreram ( $\mathrm{p}<0,001$ ) (Gráfico 7). Os 904 pacientes sobreviventes foram seguidos por período de 1 mês a 13 anos. Observamos $796(88,1 \%)$ deles em classe funcional (CF) I ou II; $84(9,3 \%)$ encontravamse em CF III e apenas $32(3,5 \%)$ em CF IV.

O reestudo hemodinâmico revelou $118(81,9 \%)$ pontes de veia safena pérvias e sem lesão; 12 $(8,3 \%)$ pontes pérvias com lesāo e $11(7,6 \%)$ ocluídas. Foram estudados 36 enxertos com artéria mamária esquerda, todos normo-funcionantes. Dentre 20 enxertos com artéria mamária direita recateterizados, 19 encontravam-se pérvios e um ocluído. Dois enxertos livres com artéria mamária reestudados também não apresentavam nenhum problema. Três enxertos com artéria epigástrica e um enxerto com artéria gastroepiplóica direita estudados revelaram-se pérvios e funcionantes.

O estudo estatístico consistiu no teste do Quiquadrado e no teste exato de Fisher, de acordo com a adequação de suas variáveis.

\section{COMENTÁRIOS}

Promovemos uma análise criteriosa de nossos resultados referentes às reoperaçōes de revascularização do miocárdio, comparando-os aos principais relatos da literatura.

A discussão desses aspectos, item por item, nos pareceu mais didática.

\section{Incidência das Reoperaçōes}

A porcentagem de reoperaçōes visando à nova revascularizaçăo do miocárdio é variável nos diversos Serviços de cirurgia cardiovascular. A tendência geral, observada nos últimos anos, é a de incidência crescente.

Há cerca de duas décadas, as reoperaçōes representavam, em média, $2,7 \%$ de todas as revascularizaçōes do miocárdio realizadas nos Centros de grande porte. Esse percentual elevou-se para $6,2 \%$ na década de $90^{19}$., 0 aumento é atribuído à ampliação nas indicaçōes de revascularizaçāo do miocárdio e aos melhores métodos empregados no diagnóstico de recidiva da insuficiência coronária. Em contrapartida, o emprego crescente de enxertos arteriais e o uso de inibidores plaquetários têm elevado a longevidade dos enxertos 4 . Esse fato, associado ao desenvolvimento de métodos alterna- tivos de revascularização miocárdica, especialmente a angioplastia coronária transluminal percutânea, tende a conter uma maior expansảo no número de reoperaçöes.

Estudo recente, realizado no Instituto do Coração, revelou que, dentre 15621 pacientes revascularizados cirurgicamente nos últimos 13 anos, 1071 $(6,85 \%)$ foram submetidos a segunda, terceira ou, mesmo, quarta operação. Em $51,5 \%$ desses pacientes, a reoperação foi realizada nos últimos três anos, demonstrando, também em nosso meio, a tendência de elevação crescente no número de cirurgias, visando à nova revascularização do miocárdio (Gráfico 1).

À semelhança das primeiras operaçōes, a revascularização do miocárdio incide, preferencialmente, no sexo masculino $(86,09 \%)$, com predomínio quase que total de pacientes da cor branca $(96,47 \%)$. Isso se deve à ampla prevalência de doença coronária nos indivíduos com essas características, em detrimento de mulheres ou de pacientes de outras raças, que raramente apresentam coronariopatia. Entretanto, nos últimos três anos, a proporção de mulheres reoperadas, embora pequena, elevou-se em $18 \%$.

As operaçōes visando à nova revascularização do miocárdio são mais freqüentes na $5^{\mathbf{a}}$ e $6^{\mathrm{a}}$ décadas de vida $(77,3 \%)$. Recentemente, porém, temos observado um crescimento no número de reoperaçōes em outras faixas de idade. Pudemos constatar que, nos últimos, a incidência de reoperaçăo na $4^{\mathrm{a}}$ década, em nosso meio, atingiu $12,79 \%$ e, na $7^{\text {a }}$ década, atingiu $9,33 \%$. Excepcionalmente, são realizadas reoperaçōes em idades mais extremas. O paciente mais jovem por nós reoperado havia completado 34 anos, enquanto o mais idoso tinha 84 anos.

\section{Indicação da Reoperaçâo}

As causas mais freqüentes que motivam a reoperaçāo estão relacionadas ao comprometimento dos enxertos venosos, seja pela hiperplasia de sua camada íntima, ou por deposição aterosclerótica em suas paredes, em concomitância com a progressāo da doença aterosclerótica nas artérias nativas. Em nosso estudo, essa associação foi responsável por $67,9 \%$ da recurrência anginosa. A oclusão parcial ou total dos enxertos isoladamente foi responsável por $17 \%$ das reoperaçōes, enquanto a progressão isolada da doença coronária motivou apenas $10,9 \%$ das mesmas (Tabela 1 ).

Temos observado outras causas menos freqüentes que podem predispor a nova revascularização do miocárdio. Em dois dos nossos pacientes houve 
DALLAN, L. A.; OLIVEIRA, S. A.; SOUZA, J. M.; JATENE, M. B.; IGLÉZIAS, J. C. R.; LEMOS, P. C. P.; AULER JÚNIOR, J. O. C.; VERGINELLI, G.; PILEGGI, F.; JATENE, A. D. - Análise de 1071 reoperaçōes para revascularizaçāo do miocárdio: resultados obtidos e conduta sugerida com base nessa experiência. Rev. Bras. Cir. Cardiovasc. 7(2):61-77, 1992.

oclusão da artéria subclávia e, conseqüentemente, com a artéria torácica interna (mamária interna), motivando a reoperação. Existem pacientes cuja revascularização primária foi associada a outros procedimentos, especialmente substituiçōes valvares. Em 1,9\% de nossa casuística, a revascularização miocárdica foi realizada, nāo como procedimento preferencial, mas aproveitando-se a oportunidade cirúrgica da reintervenção associada. Outra circunstância de reoperaçāo coronária observada em $2,0 \%$ de nossa casuística deu-se no pósoperatório imediato, decorrente de problemas técnicos com os enxertos e não conseqüente a degeneraçāo ou progressāo da aterosclerose coronária. Essas reintervençōes precoces, entretanto, não devem ser incluídas no conceito clássico de reoperaçōes em revascularização do miocárdio.

\section{Período Entre as Operaçōes}

Em nossa experiência, o intervalo observado entre a primeira e a segunda revascularização do miocárdio variou do $1^{\circ}$ ao $22^{\circ}$ ano, com média de 9,34 anos (Tabela 2). Em $80,4 \%$ desses pacientes, a reoperação ocorreu após o quinto ano, quando a progressão da doença nas artérias coronárias se somou ao comprometimento nos enxertos venosos.

LITLE et alii ${ }^{19}$ observaram período de 66 meses quando a reoperação decorreu de falência isolada nos enxertos e 90 meses, quando se associou a progressāo na aterosclerose coronária.

O intervalo entre a segunda e a terceira operaçāo variou do primeiro ao décimo-primeiro ano (média de 8,03 anos) e o período entre a terceira e a quarta operação foi de sete a nove anos (média de 7,66 anos) (Tabela 2). À semelhança da primeira reoperaçāo, as demais, em sua maioria, também ocorreram após cinco anos. A dilatação desse prazo coincide com uma etapa cirúrgica mais recente, na qual tem-se administrado, de rotina, os antiadesivitários de plaquetas e, especialmente, empregado com maior freqüência os enxertos arteriais ${ }^{18}$.

\section{Fatores de Risco Associados às Reoperaçōes}

A morbidade e a mortalidade associadas à reoperação para revascularização do miocárdio excedem às observadas nas operaçōes primárias ${ }^{9,26}$. Estudo realizado na Cleveland Clinic revelou elevação na incidência de infarto do miocárdio pré-operatório de $0,6 \%$ nas operaçōes primitivas, para $8,0 \%$ em pacientes submetidos a reoperaçōes. Nesse mesmo grupo, o risco de óbito cirúrgico elevou-se de $1,0 \%$ na revascularização miocárdica primária, para $3,4 \%$ na reoperação ${ }^{~}{ }^{\circ}$. Resultados semelhan- tes foram relatados em diversos outros Serviços de cirurgia cardiovascular, como a Mayo Clinic, o Texas Heart Institute e no estudo multicêntrico do CASS 9. 25, 27. Entretanto, devemos analisar esses dados com cautela, especialmente considerando as mudanças nas características do paciente candidato a reoperação coronária, em relação aos demais. Não raramente, a função ventricular esquerda encontrase mais comprometidd do que a dos pacientes submetidos primariamente a revascularizaçāo miocárdica. No próprio estudo da Cleveland Clinic, podemos observar que apenas $34 \%$ dos pacientes reoperados apresentavam função normal de VE; $81 \%$ dos pacientes apresentavam lesōes triarteriais ou de tronco de coronária esquerda, e a faixa etária era significativamente mais elevada do que a dos pacientes operados primariamente, contribuindo direta ou indiretamente para maiores complicaçōes no intra e no pós-operatório. Torna-se, portanto, necessário um teste de análise multivariada para se tirar conclusōes do verdadeiro risco inerente às reoperaçōes.

Por outro lado, recentes estudos têm demonstrado decréscimos progressivos nas complicaçōes e na mortalidade relativas à população reoperada 9.16 . 18. 24 . Isso se deve, especialmente, a maior experiência cirúrgica e anestésica adquiridas no decorrer dos anos. A indicação cirúrgica mais precoce, os cuidados técnicos com a toracotomia, especialmente evitando-se embolias coronárias decorrentes da manipulação de pontes de veia safena já degeneradas, a proteção miocárdica mais adequada e a revascularizaçăo completa do miocárdio têm, também, contribuído, decisivamente, para a melhoria dos resultados cirúrgicos.

Em recente estudo, procuramos correlacionar os fatores de risco mais freqüentemente associados à coronariopatia, com a mortalidade cirúrgica na reoperaçāo. A ocorrência de diabete, hipertensão arterial sistêmica, hipercolesterolemia, obesidade, insuficiência renal crônica, tabagismo, história familiar, stress e vida sedentária foi considerada para cada paciente.

Verificamos que 731 pacientes apresentavam até dois fatores considerados de risco, dos quais 35 $(4,8 \%)$ faleceram no período hospitalar. Dentre 299 pacientes com três ou quatro desses fatores, 38 $(12,7 \%)$ vieram a falecer. Dentre os 41 pacientes restantes, portadores de cinco ou mais fatores de risco, observamos $14(34,1 \%)$ óbitos, o que representou variação estatisticamente significativa $(p<0,001)$.

Existem, entretanto, situaçōes clínicas que podem, ou não, estar associadas a maior morbidade e mortalidade cirúrgicas, que passaremos a analisar: 
DALLAN, L. A.; OLIVEIRA, S. A.; SOUZA, J. M.; JATENE, M. B.; IGLÉZIAS, J. C. R.; LEMOS, P. C. P.; AULER JÚNIOR, J. O. C.; VERGINELLI, G.; PILEGGI, F.; JATENE, A. D. - Análise de 1071 reoperaçōes para revascularizaçāo do miocárdio: resultados obtidos e conduta sugerida com base nessa experiência. Rev. Bras. Cir. Cardiovasc. 7(2):61-77, 1992.

\section{Classe funcional (angina) pré-operatória}

Existem, na literatura, evidências claras de que pacientes situados em classe funcional (CF) IV (NYHA) apresentam significativo aumento no risco cirúrgico, especialmente quando associadas a lesão no tronco da coronária esquerda ${ }^{19}$.

Isso também foi observado na nossa experiência (Gráfico 2). Verificamos que a mortalidade operatória de 2,2\% em pacientes em CF I e II, elevouse para $7,6 \%$ e $15,1 \%$ em pacientes situados, respectivamente, em CF III e IV ( $<<0,001)$.

\section{Fração de ejeçāo de ventrículo esquerdo}

A exemplo das revascularizaçōes primitivas do miocárdio, o comprometimento moderado ou severo na função do ventrículo esquerdo tem elevada influência nos resultados imediatos e tardios, quando da re-revascularização do miocárdio. A mortalidade pré-operatória significativamente de $4,2 \%$ em pacientes com fração de ejeção situada acima de $30 \%$, determinada através da angiografia eșquerda, para $18,1 \%$ naqueles cuja fração encontrava-se igual ou inferior a $30 \%(p<0,001)$ (Gráfico 2$)$.

\section{Procedência do paciente}

Temos observado maior mortalidade na reoperaçăo de pacientes cuja primeira operação foi realizada em outros Serviços, quando comparados àqueles em que a operação inicial se deu na própria Institutiçāo. A explicação se fudamenta no melhor seguimento proporcionando pela Instituição a esses pacientes, após a primeira operaçāo. Através de consultas periódicas, é possível o controle adequado da pressão arterial, a orientação alimentar e medicamentosa e, especialmente, ao fato de se detectarem precocemente, sinais de isquemia miocárdica, permitindo, caso necessário, programar nova revascularização miocárdica, ainda com a função ventricular preservada.

Nesse sentido, observamos $4,03 \%$ de óbitos pré-operatórios de pacientes operados primariamente na nossa Instituiçāo, contra $9,2 \%$ daqueles oriundos de outros Serviços $(p=0,012)$.

\section{Período entre as operaçōes}

A influência do intervalo entre as revascularizaçōes do miocárdio como fator determinante na mortalidade operatória vem sendo destacada por alguns autores ${ }^{20,26 .}$

SALOMON et alii ${ }^{28}$ relataram elevaçāo na taxa de mortalidade imediata de $6,0 \%$, quando a reoperaçāo foi realizada entre o primeiro e o décimo ano, para $17,6 \%$ caso já houvessem transcorrido mais de 10 anos da revascularização primitiva. Atribuíram essa discrepância à doença aterosclerótica intensa e difusa observada nas artérias nativas e nos enxertos venosos. Nossos resultados năo corroboram essa afirmativa. Nosso estudo não demonstrou variaçāo significativa entre qualquer intervalo de nossas reoperaçōes $(p=0,375)$ (Tabela 2).

\section{Terceira e quarta revascularizaçōes do miocárdio}

Na prática médica, tem-se observado um pequeno número de pacientes já submetidos a duas ou mais operaçōes para revascularização do miocárdio, que voltam a apresentar sintomas de angina, apesar de esgotados os recursos clínicos para seu tratamento. Resta a dúvida referente à validade de nova reintervenção. Os dados de literatura mostram-se favoráveis a essas reintervençōes. OWEM $\mathrm{Jr}$. et alii ${ }^{23}$, em estudo específico, ressaltaram a validade desses procedimentos, especialmente envolvendo artérias coronárias nativas ainda não revascularizadas, ou objetivando substituir pontes de veia safena parcial ou totalmente ocluídas. A baixa morbidade e mortalidade observadas pelos autores endossam essas afirmaçōes. Em nosso grupo, constatamos 53 pacientes revascularizados pela terceira vez e três pela quarta vez, com a mortalidade operatória, respectivamente, de $7,5 \%$ e 0\% (Gráfico 5).

O seguimento tardio desses pacientes foi bastante favorável, o que vem reforçar a indicação cirúrgica em casos semelhantes.

\section{Tipos de enxertos utilizados nas reoperaçōes}

A exemplo das revascularizaçōes miocárdicas primitivas, nas reoperaçōes, podemos empregar a veia safena magna, a artéria torácica interna e outros enxertos arterias, como a artéria gastroepiplóica direita e a artéria epigástrica inferior. Como enxertos alternativos têm sido utilizados a veia safena parva, as veias do braço, os enxertos sintéticos de politetrafluoretileno expandido e a veia umbilical preservada em glutaraldeído.

O emprego de enxertos arterias nas reoperaçōes elevou-se significativamente, nos últimos anos. Hoje, já há consenso de que o uso da artéria torácica interna não eleva a taxa de morbidade ou mortalidade da reoperação, mesmo em se tratando de pacientes portadores de lesão no tronco da coronária esquerda ${ }^{19}$. Ao contrário, a simples revascularização da artéria interventricular anterior através da artéria 
DALLAN, L. A.; OLIVEIRA, S. A.; SOUZA, J. M.; JATENE, M. B.; IGLÉZIAS, J. C. R.; LEMOS, P. C. P.; AULER JÚNIOR, J. O. C. VERGINELLI, G.; PILEGGI, F.; JATENE, A. D. - Análise de 1071 reoperaçōes para revascularizaçäo do miocárdio: resultados obtidos e conduta sugerida com base nessa experiência. Rev. Bras. Cir. Cardiovasc. 7(2):61-77, 1992.

torácica interna esquerda tem sido descrita como um fator que contribui de maneira eficaz no alívio da angina e na melhora da sobrevida ${ }^{18,22}$. Recomenda-se, portanto, sempre que possível, o empre. go de uma ou de ambas as artérias como rotina nas reoperaçōes ${ }^{26}$.

Em nosso meio, também temos dado preferência aos enxertos arteriais. Dentre 1071 reoperaçōes realizadas nos últimos 13 anos, em 610 (56,9\%) utilizou-se enxerto com uma artéria torácica interna, em $192(17,9 \%)$ foram empregadas ambas, em 6 $(0,6 \%)$ utilizou-se a artéria gastroepiplóica direita e, em $5(0,5 \%)$, a artéria epigástrica, perfazendo um total de $813(75,9 \%)$ operaçōes em que se empregou ao menos 1 enxerto arterial. Se considerarmos apenas os últimos dois anos, essa taxa eleva-se a $82,2 \%$ (Tabela 4 ).

A utilização da artéria torácica interna direita in situ muitas vezes apresenta dificuldades técnicas para atingir determinados ramos coronários, especialmente se localizados na parede lateral do ventrículo esquerdo. O artifício de posicioná-la por via retro-aórtica, amplamente empregado nas operaçōes primitivas, pode estar dificultado por aderências locais ou pela menor mobilizaçāo do coraçāo, observada nas reoperaçōes. A alternativa, nesses casos, é o enxerto livre, através da secção da artéria junto à origem na artéria subclávia e anastomose de seu coto proximal na aorta, de maneira direita ou sobre segmento de veia safena. Como vantagem adicional desse método, destacamos o uso de um segmento mais curto da artéria, obtendo-se, conseqüentemente, um enxerto arterial mais calibroso.

O emprego de veia safena do próprio paciente nas reoperaçōes também deve ser considerado. A dificuldade técnica muitas vezes se faz presente, especialmente devido às aderências ou à má qualidade das artérias coronárias, o que, freqüentemente, exige que a revascularização seja complementada com esse tipo de enxerto.

O número de enxertos por pacientes nas reoperaçōes habitualmente é inferior aos realizados na revascularizaçāo primitiva ${ }^{26}$. Nossa média de enxertos na segunda, terceira e quarta revascularizaçōes do miocárdio foi, respectivamente, de $2,47,2,41$ e 2,33 enxertos por paciente. A avaliaçăo cuidadosa pré-operatória da cinecoronariografia e a identificaçāo da artéria revascularizada previamente, especialmente acompanhando-se o trajeto da porção estenótica ou ocluída, auxiliam, consideravelmente, na identificaçāo das artérias coronárias a serem tratadas na reoperaçāo ${ }^{27}$. Isso permite a realizaçāo de maior número de enxertos, prevenindo-se os riscos da revascularização incompleta 5,15 .

\section{TÉCNICA OPERATÓRIA}

\section{Aspectos Gerais}

A experiência crescente adquirida com as reoperaçōes têm permitindo minimizar suas dificuldades técnicas.

A suspensão de uso da aspirina e similares, caso o quadro clínico do paciente permita, é recomendável sete a dez dias antes da reoperação, no sentido de diminuir o sangramento intra-operatório.

A circulação extracorpórea tem sido empregada como rotina nas reoperaçōes, associadas a hipotermia moderada.

\section{Reoperaçōes de Urgência}

Medidas adicionais visando oferecer maior segurança ao procedimento cirúrgico devem ser adotadas nos pacientes com instabilidade hemodinâmica. A artéria e veia femorais devem ser expostas ou, mesmo, canuladas previamente à toracotomia, o que possibilita a imediata instalação da circulação extraorpórea, caso necessário. Os tubos do circuito extracorpóreo devem estar ordenados no campo cirúrgico e seu reservatório preenchido. A sala operatória deve conter desfibrilador com pás externas e internas. Há, inclusive, quem preconize a colocação de uma pá não estéril sob o tórax do paciente, de maneira que uma eventual desfibrilação possa ser realizada em associaçāo com outra pá estéril, posicionada na parede anterior do tórax, evitando-se uma dissecção mais extensa do coraçāo ${ }^{28}$. Paralelamente, a veia safena deve ser retirada e preparada para uma rápida anastomose, assim que expostas as artérias coronárias a serem revascularizadas. $O$ uso de cell-saver é recomendável nesses casos. O maior volume sangüíneo extravasado no campo, após a heparinização precoce, pode ser parcialmente compensado pelo reaproveitamento de suas hemácias, que são lavadas e centrifugadas.

\section{Reoperações Eletivas}

Nas reoperaçōes eletivas, a toracotomia mediana pode ou não ser associada a exérese da cicatriz antiga. A observaçăo de radiografias do tórax permite localizar e enumerar os fios de aço, que são seccionados e retirados. A secçāo longitudinal do esterno deve ser cautelosa, utilizando-se serra com lâmina circular e cuidando-se para que a mesma não ultrapasse a tábua posterior do esterno. Devese, também, evitar a dissecção digital da regiẫo 
DALLAN, L. A.; OLIVEIRA, S. A.; SOUZA, J. M.; JATENE, M. B.; IGLÉZIAS, J. C. R.; LEMOS, P. C. P.; AULER JÚNIOR, J. O. C.; VERGINELLI, G.; PILEGGI, F.; JATENE, A. D. - Análise de 1071 reoperaçōes para revascularizaçāo do miocárdio: resultados obtidos e conduta sugerida com base nessa experiência. Rev. Bras. Cir. Cardiovasc. 7(2):61-77, 1992.

retro-esternal. Após a completa secção do esterno, procede-se à liberação das aderências presentes. Essa dissecçăo deve ser realizada com o auxílio do bisturi elétrico, progredindo-se em direção a ambas as pleuras, que são amplamente abertas de rotina. Um erro cometido com freqüência por cirurgiōes menos experientes consiste na colocação e abertura de afastadores torácicos antes de liberarem-se totalmente as aderências mediastinais. Essa manobra pode acarretar esgarçamento do ventrículo direito, seguido de hemorragias muitas vezes incontroláveis 7,17 .

A instalaçāo da circulação extracorpórea é possível, na maioria das vezes, pela introdução de cânula arterial na aorta ascendente e drenagem venosa por tubo único multiperfurado, posicionado através do átrio direito, sem necessidade de dissecçăo das veias cavas.

\section{Cuidados com os Enxertos Venosos}

Especial atenção deve ser dada ao manuseio cardíaco durante a reoperação. Até mesmo mínimas manipulaçōes podem levar a embolizaçōes coronárias pelos detritos ateroscleróticos comumente acumulados no interior dos enxertos venosos, especialmente se não totalmente ocluídos (Figura 1). Recomenda-se a sua ligadura antes ou imediatamente após abertura da veia comprometida ou da artéria coronária correspondente " ${ }^{p}$. Existem Serviços que recomendam a substituição de todos os enxertos venosos realizados há mais de cinco anos 11. 20. Esses autores baseiam-se na observação de graus avançados de aterosclerose na camada íntima desses enxertos, freqüentemente difusos e

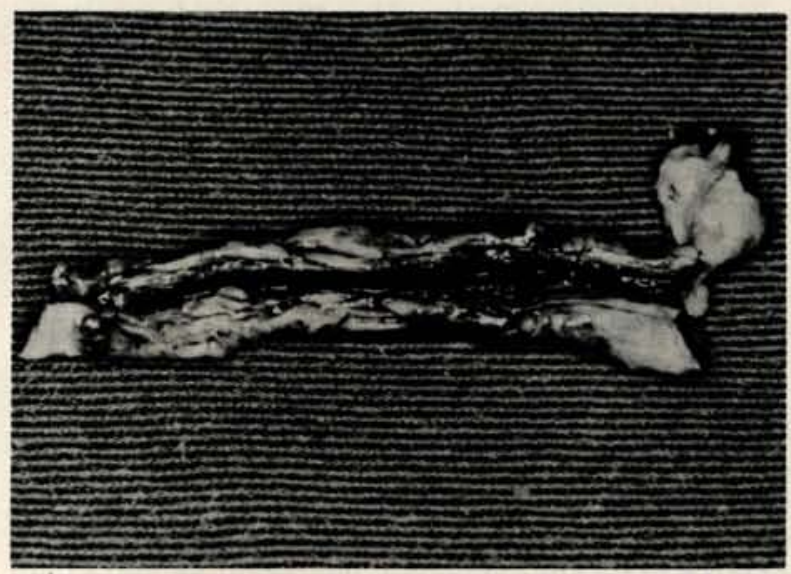

Fig. 1 - Aspecto da veia safena utilizada por 12 anos como enxerto aorto-coronário. Nota-se grande dilatação, com hipertrofia de suas camadas e acentuada degeneraçáo aterosclerótica. inclusive com trombos em sua luz. friáveis e que, invariavelmente, são subestimados pelos estudos angiográficos ${ }^{15}, 19$.

Outro método que permite minimizar a possibilidade de embolização coronária consiste na realização das anastomoses proximais e distais em pinçamento único da aorta, com o auxílio da solução cardioplégica ${ }^{30}$.

Por outro lado, inúmeros pacientes têm seu suprimento sangüíneo coronário dependente de enxertos venosos, deviđo a obstruçāo severa ou total de suas artérias coronárias. A lesão desses enxertos na abertura torácica ou durante a dissecção cardíaca pode acarretar extenso infarto do miocárdio, elevando, significativamente, o risco operatório.

\section{Manuseio da Artéria Torácica Interna}

A presença de enxertos pérvios e funcionantes de artéria torácica, interna também exige cuidados adicionais nas reoperaçōes. Deve-se evitar, na fase de abertura torácica, a dissecção de tecidos ou aderências localizadas no provável trajeto da artéria. A simples palpação desses tecidos muitas vezes pode levar a conclusōes errôneas, pois seu pulso pode estar mascarado por aderência, propiciando sua secção inadvertida. Por outro lado, já observamos diminuição acentuada no fluxo dessas artérias funcionantes, ao afastarmos excessivamente as bordas do esterno, devido ao seu estiramento, com sofrimento miocárdico agudo e conseqüente hipotensāo arterial. A reversão do quadro é facilmente obtida pelo simples fechamento parcial do afastador, promovendo-se o relaxamento das estruturas torácicas. Entretanto, esse mecanismo muitas vezes passa despercebido e o quadro é tratado através da administração de altas doses de drogas vasopressoras, o que, invariavelmente, compromete o sucesso da cirurgia.

A presença de enxertos pérvios de artéria torácica interna aumenta a dificuldade técnica nas reoperaçōes. Seu fluxo sangüíneo persistente, apesar do pinçamento aórtico, faz com que haja sangramento contínuo nas demais artérias e no campo operatório. A soluçâo cardioplégica infundida diretamente no coraçăo também perde rapidamente sua ação protetora. A soluçāo alternativa é - pinçamento temporário do pedículo da artéria, porém tendo-se em mente a sua extrema fragilidade estrutural e o elevado risco que envolve a sua dissecção.

\section{Proteção Miocárdica}

Inúmeras complicaçōes pós-operatórias podem ser atribuídas à dificuldade em estabelecer-se uma 
DALLAN, L. A.; OLIVEIRA, S. A.; SOUZA, J. M.; JATENE, M. B.; IGLÉZIAS, J. C. R.; LEMOS, P. C. P.; AULER JÚNIOR, J. O. C.; VERGINELLI, G.; PILEGGI, F.; JATENE, A. D. - Análise de 1071 reoperaçōes para revascularizaçāo do miocárdio: resultados obtidos e conduta sugerida com base nessa experiência. Rev. Bras. Cir. Cardiovasc. 7(2):61-77, 1992.

proteção miocárdica adequada durante a reoperação de revascularização coronária. $O$ próprio período decorrente entre a indução da anestesia, o início da circulação extracorpórea e o funcionamento efetivo dos novos enxertos podem propiciar danos miocárdicos. Isso explica a incidência mais elevada de infarto do miocárdio trans-operatório nesses pacientes, em relação aos submetidos à primeira operação.

O emprego de soluçōes cardioplégicas, preconizado pela maioria dos Serviços de cirurgia cardiovascular, também apresenta inúmeros problemas. A infusão da solução através das artérias nativas comprometidas não oferece proteção ideal aos territórios isquêmicos. Enxertos ocluídos ou estenóticos também não proporcionam fluxo adequado a essas regiōes, além de elevarem o risco de embolizaçāo. A infusāo de solução cardioplégica retrogradamente, através do seio coronário, auxilia na proteção miocárdica. Entretanto, o método exige dissecçāo do átrio direito e canulação com garroteamento de ambas as veias cavas, ampliando a área de descolamento do coraçāo ${ }^{8}$.

Diante desses fatos, temos preferido, inicialmente, anastomosar os enxertos venosos nas artérias coronárias de maior importância, seja pelo seu grau de oclusão ou pela extensão do território que irrigam. Em seguida, é infundida solução cardioplégica através desse enxerto, ou o mesmo é ligado a um perfusor contendo sangue oxigenado proveniente da linha arterial da circulação extracorpórea, caso tenha-se optado pelo pinçamento aórtico intermitente. Esse procedimento deve ser estendido às demais artérias a serem revascularizadas. As anastomoses proximais são realizadas de maneira clássica, através do pinçamento aórtico intermitente ou, ainda, sob pinçamento único, caso tenha-se optado por cardioplegia.

Recentemente, pudemos verificar, em nossa casuística, acentuada queda na mortalidade operatória das reoperaçōes coronárias. Nos últimos dois anos, foram realizadas 379 revascularizaçōes do miocárdio, tendo sido observados apenas $13(3,4 \%)$ óbitos, taxa significativamente inferior aos $10,7 \%$ de óbitos constatados nos anos anteriores $(p<0,001)$ (Gráfico 7). Essa variação não foi conseqüente a um procedimento isolado, mas sim a um conjunto de medidas que envolveram desde cuidados pré e pós-operatórios mais intensivos, até mudanças táticas na abordagem cirúrgica dos pacientes. Entretanto, devemos reconhecer que a queda na mortalidade pré-operatória, em grande parte, decorreu da melhor proteção proporcionada ao miocárdio isquêmico.

Os resultados cirúrgicos imediatos, observados no início de nosso estudo, mostram valores bastan- te semelhantes entre os pacientes operados com pinçamento aórtico intermitente e aqueles operados, com o emprego de soluçāo cardioplégica. Entretanto, nos últimos dois anos, a queda na mortalidade coincidiu com o uso, na maioria dos pacientes reoperados, de soluçāo cardioplégica sangüínea e enriquecida com os aminoácidos aspartato e glutamento (Gráfico 6). Embora ainda sem significado estatístico $(p=0,470)$, esses resultados sugerem melhor proteção miocárdica, estimulando seu emprego nas reoperaçōes, especialmente visando aos pacientes com maior instabilidade hemodinâmica.

\section{Complicaçōes Intra e Pós-Operatórias}

A morbidade inerente às reoperaçōes em revascularizaçāo do miocárdio é mais elevada do que a observada nas operaçōes primárias. Complicaçōes importantes têm sido relatadas em $5 \%$ a $15 \%$ dos pacientes reoperados ${ }^{27}$. Entretanto, ao considerarse que esses pacientes freqüentemente têm doença arterial mais severa $e$ as dificuldades técnicas inerentes ao procedimento cirúrgico, os resultados relatados em diversos estudos têm sido considera: dos bastante satisfatórios 2, 16, 21 .

A complicação mais freqüente observada em nossa casuística correspondeu a infeç̧ão $(9,5 \%)$. $\mathrm{Na}$ maioria dos pacientes era limitada aos membros inferiores, local da retirada do enxerto venoso. Grande parte dos pacientes já possuía seus membros inferiores manipulados nas operaçōes pregressas, e variaçōes na rotina cirúrgica, buscando um segmento de veia safena magna ou parva, justificaram o elevado índice de infecçāo que, felizmente, teve resolução satisfatória em sua totalidade de casos. Entretanto, $8(0,74 \%)$ pacientes apresentaram mediastinite pós-operatória, necessitando reintervençāo cirúrgica para limpeza e instalaçāo de lavagem contínua no mediastino, dos quais 6 vieram a falecer.

O infarto pré-operatório foi a complicação mais grave das reoperaçōes. $O$ risco de sua ocorrência é, reconhecidamente, mais elevado do que nas operaçōes iniciais e sua incidência é variável em diversos relatos. Grandes Centros de cirurgia cardiovascular, como Mayo Clinic e a Cleveland Clinic, constataram, em levantamentos recentes, porcentuais de, respectivamente, $7,5 \%$ e $8,0 \%$ na ocorrência de infartos pré-operatórios ${ }^{10,27}$.

Observamos, em nosso grupo, incidência de infarto pré-operatório em $8,1 \%$ dos pacientes reoperados, determinados através de alteração do ECG e/ou elevaçāo de CKMB. Embora o motivo exato desse maior risco em relaçāo às operaçōes primárias nāo esteja totalmente claro ${ }^{16}$, sua causa 
DALLAN, L. A.; OLIVEIRA, S. A.; SOUZA, J. M.; JATENE, M. B.; IGLÉZIAS, J. C. R.; LEMOS, P. C. P.; AULER JÚNIOR, J. O. C.; VERGINELLI, G.; PILEGGI, F.; JATENE, A. D. - Análise de 1071 reoperaçōes para revascularizaçāo do miocárdio: resultados obtidos e conduta sugerida com base nessa experiência. Rev. Bras. Cir. Cardiovasc. 7(2):61-77, 1992.

provável deve estar relacionada às dificuldades na identificação das artérias às aderências pericárdicas e pela avançada doença coronária. ASSAD-MORELL et alii ${ }^{1}$ relataram que $25 \%$ dos infartos transmurais pós-operatórios ocorreram em áreas de artérias com doença aterosclerótica não revascularizadas.

Essas observaçōes nos levam a concluir que o infarto trans-operatório nāo decorre apenas de faIhas no sistema de proteção miocárdica, mas também está associado a possíveis embolizaçōes por detritos dos enxertos antigos ainda pérvios e, especialmente, à revascularização miocárdica incompleta freqüentemente observada nas reoperaçōes.

Complicaçōes respiratórias e renais também ocorrem com relativa freqüencia no pós-operatório das reoperaçōes (respectivamente $7,8 \%$ e $4,8 \%$ em nossa casuística), mas geralmente se restringem aos pacientes já portadores de deficiência crônica no funcionamento desses órgāos. A utilização de aparelhos respiratórios mais modernos, a instalação precoce de diálise peritoneal e de ultrafiltraçāo sangüínea, muitas vezes já acoplada ao sistema de circulação extracorpórea, têm auxiliado a atenuar essas complicaçōes. Em pacientes portadores de doença pulmonar obstrutiva crônica que evoluem com infecção respiratória e sem perspectiva de extubação a médio prazo, temos indicado precocemente a traqueostomia, com bons resultados.

O sangramento cirúrgico constitui motivo de preocupação em qualquer reoperação. As aderências pericárdicas e mediastinais predispōem a maior sangramento intra e pós-operatório, elevando a necessidade de reintervençāo para revisão de hemostasia ( $4,9 \%$ em nossa casuística). Entretanto, as hemorragias abruptas decorrentes de lesōes durante toracotomia podem ter conseqüências catastróficas, se não forem bem conduzidas. Na presença de hemorragia grave, a insistência em suturarse o local sangrante sem sua exposiçāo ideal, ou a rápida abertura do esterno e dissecçāo romba do coração podem extender a área de laceração e ampliar o sangramento, tornando-o incontrolável. Recomenda-se, nesses casos, a compreensão digital do local sangrante e, após heparinizaçāo, a instalação de circulação extracorpórea por via femoral, que permitirá o reaproveitamento sangüíneo e a manutenção das condiçōes hemodinâmicas. Essas medidas minimizaram, em nosso meio, os efeitos das hemorragias na mortalidade e na má evolução hospitalar dos pacientes. Por outro lado, - emprego sistemático intra e pós-operatório de cell-saver e de auto-transfusão tem reduzido, não só a necessidade de revisōes cirúrgicas das toracotomias, como também a administração de sangue e seus derivados. SALOMON et alii ${ }^{26}$ relataram que, através dessas medidas, a média de uso sangüíneo reduziu-se a menos de duas bolsas por pacientes e que, aproximadamente em $50 \%$ das reoperaçōes, não se empregou sangue homólogo.

As complicaçōes neurológicas e abdominais são pouco freqüentes e transitórias em sua maioria. Diante de distensão abdominal e adinamia intestinal prolongadas, temos indicado a arteriografia mesentérica com posicionamento de cateter local, visando à infusão contínua e prolongada de papaverina intraarterial.

\section{Causas de Óbito}

A disfunção ventricular é a responsável por praticamente $50 \%$ dos óbitos hospitalares das nossas reoperaçōes visando a nova revascularização do miocárdio. Os novos métodos de abordagem cirúrgica e proteção miocárdica reduziram, como já citado, a mortalidade de $10,7 \%$ para $3,4 \%$ nos últimos dois anos (Gráfico 7). Entretanto, outras medidas terapêuticas têm auxiliado na obtenção desses resultados. A passagem de rotina dos cateteres de Swan-Ganz, ainda no pré-operatório, tem permitido detectar e tratar precocemente sinais de baixo débito cardíaco. O emprego do balāo intraaórtico tem sido mais ostensivo, especialmente pela facilidade de sua instalação transcutânea e permanência mais prolongada. A bomba centrífuga tem, igualmente, permitido assistência circulatória prolongada aos pacientes com disfunçāo ventricular severa.

As demais causas de óbito decorreram especialmente de complicaçōes pulmonares, que tendem a se agravar na segunda e terceira semanas de pós-operatório.

\section{Evoluçāo Tardia}

A literatura tem demonstrado excelentes taxas de sobrevida em pacientes submetidos a nova revascularizaçāo miocárdica ${ }^{27}$. LITLE et alii ${ }^{19}$, em extensa série de pacientes, observaram que $90 \%$ dos pacientes que obtiveram alta hospitalar encontravam-se vivos após cinco anos e $75 \%$ ao final de dez anos. Esses resultados são apenas discretamente inferiores aos obtidos nas operaçōes primárias ${ }^{6}$ e semelhantes aos que observamos em nossa casuística. A maior mortalidade correspondeu aos pacientes idosos e com má fração de ejeção ${ }^{6,26}$. Esse achado, entretanto, não é peculiar apenas às reoperaçōes visando a nova revascularizaçāo miocárdica, uma vez que esses fatores, reconhecidamente, diminuem a sobrevida tardia de outras doenças cardiacas adquiridas, seja sob tratamento clínico ou cirúrgico ${ }^{19}$. Por outro lado, esses mes- 
DALLAN, L. A.; OLIVEIRA, S. A.; SOUZA, J. M.; JATENE, M. B.; IGLÉZIAS, J. C. R.; LEMOS, P. C. P.; AULER JÚNIOR, J. O. C.; VERGINELLI, G.; PILEGGI, F.; JATENE, A. D. - Análise de 1071 reoperaçōes para revascularizaçāo do miocárdio: resultados obtidos e conduta sugerida com base nessa experiência. Rev. Bras. Cir. Cardiovasc. 7(2):61-77, 1992.

mos autores observaram que $85 \%$ dos pacientes reoperados com idade superior a 70 anos encontravam-se vivos após três anos, e $82 \%$ dos pacientes com má funçāo ventricular pré-operatória sobreviviam ao final de cinco anos, sugerindo a validade da nova intervenção cirúrgica até nesse grupo de pacientes.

O seguimento tardio dos pacientes reoperados demonstra que metade deles apresenta algum tipo de sintoma cardíaco após cinco anos de pós-operatório ${ }^{19}$, enquanto apenas $30 \%$ dos pacientes encontram-se assintomáticos decorridos 10 anos ${ }^{26}$.

Entretanto, esses sintomas são, em sua maioria, leves, reservando os sintomas severos a um pequeno número de pacientes.

Em nossa casuística, a grande maioria dos sobreviventes evoluiu em classe funcional I ou II. Apenas $18,8 \%$ deles encontram-se em classe funcional III ou IV. Podemos considerar esses resultados bastante favoráveis, embora mais da metade dos pacientes de nosso estudo tenham menos de três anos de pós-operatório.

O pequeno número de reestudos hemodinâmicos realizados nāo nos permite tirar conclusōes estatisticamente significativas, referentes ao comportamento dos enxertos nas reoperaçōes. Isso porque esses pacientes já foram submetidos no mínimo a dois cateterismos cardíacos e, em geral, um novo estudo hemodinâmico somente é deflagrado na vigência de novos sintomas cardíacos. Entretanto, apesar dessa condiçăo, mais de $80 \%$ dos enxertos com veia safena reestudados em nosso grupo apresentavam-se pérvios e sem lesão. Essa observação, associada aos recentes estudos da ação favorável dos inibidores plaquetários na preservação do endotélio venoso ${ }^{4}$, pressupōe grande longevidade a esses enxertos.

Por outro lado, a despeito do pequeno número de pacientes reestudados, os excelentes índices de perviabilidade dos enxertos com artéria torácica interna observados na primeira revascularizaçāo vêm se repetindo nas reoperaçōes. Isso está demonstrado em nosso grupo e na literatura ${ }^{19} \mathrm{e}$ vem estimulando cada vez mais o emprego de enxertos arteriais nas revascularizaçōes. Nos últimos dois anos, utilizamos ao menos um enxerto arterial em $82,2 \%$ de nossos pacientes (Tabela 4).

Acreditamos que, através da abordagem cirúrgica adequada e criteriosa, como amplamente sugerida, associada ao emprego crescente de enxertos arteriais e, especialmente, pela indicação cirúrgica precoce, permitindo a nova revascularizaçāo de forma eletiva e, ainda, com boa viabilidade miocárdica, os resultados futuros serāo altamente promissores.

DALLAN, L. A.; OLIVEIRA, S. A.; SOUZA, J. M.; JATENE, M. B.; IGLÉZIAS, J. C. R.; LEMOS, P. C. P.; AULER JÚNIOR, J. O. C.; VERGINELLI, G.; PILEGGI, F.; JATENE, A. D. - Evaluation of 1071 reoperations for myocardial revascularization. Rev. Bras. Cir. Cardiovasc. 7(2):61-77, 1992.

ABSTRACT: Between January 1979 and January 1992, 1071 coronary bypass graft reoperations were performed at the Heart Institute and Beneficencia Portuguesa Hospital. Of these, 1015 were reoperated upon once, 53 twice and 3 three times. The surgeries were due to spread of coronary atherosclerosis in 117 patients $(10.9 \%)$, partial or total graft occlusion in $183(17.1 \%)$, combination of the prior factors in $728(67.9 \%)$, technical problems in $21(1.9 \%)$, and others in $22(2.1 \%)$. The patients ages varied from 34 to 84 years (mean 61.6$)$, predominantly male $(86.1 \%)$ and Caucasian $(96.5 \%)$. The period between the first and second operations varied from the same day to 22 years after (mean $9,3 \%$ ), the second and third from one to 11 years (mean 8.0 ) and between the third and fourth seven to nine years (mean 7.7). During the surgical procedures: one mammary artery in $610(56.9 \%)$ cases, both mammary arteries in $192(17.9 \%)$, gastroepiploic arteries in six $(0.6 \%)$ and epigastric arteries in five $(0.5 \%)$ were used. In $813(75.9 \%)$ of the 1071 reoperations at least one arterial graft was employed in the coronary bypass grafts. There were $87(8.1 \%)$ hospital deaths in this period, of which $39(44.8 \%)$ were directly related to ventricle dysfunction, and $48(55.2 \%)$ caused by other complications: pulmonary 22 , sepsis 8 , coagulation 7, neurologic 6 and mesenteric ischemia 5. The principal factors associated to mortality were: I) preoperative risk factors were: diabetes, hypertension, high colesterol, obesity, smoking, hereditary history, etc.; 731 patients presented up to two risk factors with 35 deaths $(4.8 \%) ; 299$ presented three or four with $38(12.7 \%)$ deaths and in 4 patients there were five or more risk factors, with $14(34.1 \%)$ deaths; 2) preoperative functional class: 317 were in class I or II, $11(3.5 \%)$ of which died; 449 were in class III, $39(8.7 \%)$ having died; and 305 in class IV with $46(15.1 \%)$ deaths. Triarterial vessels compromised 
DALLAN, L. A.; OLIVEIRA, S. A.; SOUZA, J. M.; JATENE, M. B.; IGLÉZIAS, J. C. R.; LEMOS, P. C. P.; AULER JÚNIOR, J. O. C.; VERGINELLI, G.; PILEGGI, F.; JATENE, A. D. - Análise de 1071 reoperaçōes para revascularizaçāo do miocárdio: resultados obtidos e conduta sugerida com base nessa experiência. Rev. Bras. Cir. Cardiovasc. 7(2):61-77, 1992.

\begin{abstract}
associated or not to main trunk lesion: 788 presented this complication, of which $74(9.4 \%)$ died. Among 283 characterized by uni or biarterial lesions, $13(4.3 \%)$ having died; 3$)$ surgery status: 110 emergency operations with 35 deaths $(31.8 \%), 961$ elective surgeries $52(5.4 \%)$ having died. In the last two years, however, 379 coronary bypass graft reoperations were performed with only 13 deaths $(3.5 \%)$. This decreased in mortality in relation to the preceding years was attributed, among other factors, to the improved methods of myocardial protection, especially in patients with worse ventricle condition. It was also emphasized in the last two years the arterial graft usage in the reoperations. Mean usage of at least one arterial graft in the reoperations was $82.2 \%$. It is strongly believed that the best results can be reached through adequate surgical handling, increased employment of the arterial graft and especially avoiding emergency situations by earlier reoperation.
\end{abstract}

DESCRIPTORS: myocardial revascularization, reoperation.

\section{REFERÊNCIAS BIBLIOGRÁFICAS}

1 ASSAD-MORELL, J. L.; CONNOLY, D. C.; GAU, G. T.; WALLACE, R. B.; DAVIS, G. D.; EVELBACK, L: R.; DANIELSON, G. K. - Relation of intraoperative or early postoperative transmural myocardial infarction to patency of aortocoronary bypass grafts and to diseased ungrafted coronary arteries. Am. J. Cardiol., 35:767-773, 1975.

2 BROOKS, N.; HONEY, M.; CATTELL, M.; WRIGHT, J. E. C.; STURRIDGE, M. F.; BALCON, R.; LAYTON, C. - Reoperation for current angina. Br. Heart J., 42:333-338, 1979.

ChAITMAN, B. R.; ROGERS, W. J.; DAVIS, K. Operative risk factors in patients with left main coronary artery disease. N. Engl. J. Med., 303:953957, 1980.

4 CHESEBRO, J. H.; CLEMENTS, I. P.; FUSTER, V.; EVELBACK, L. R.; SMITH, H. C.; BARDSLEY, W. T.; FRYE, R. L.; HOLMES Jr., D. R.; VLIESTRA, R.E.; PLUTH, J. R.; WALLACE, R. B.; PUGA, F. J.; ORSZULLAK, T. A.; PIEHLER, J. M.; SCHAFF, H. V.; DANIELSON, G. K. - A platelet-inhibitor-drug trial in coronary-artery bypass operations: benefit of perioperative dupyridamole and aspirin therapy on early postoperative vein-graft patency. N. Engl. J. Med.; 307:73-78, 1982.

COSGROVE, D. M.; LOOP, F. D.; LYTLE, B. W. - An 11 -year evolution of coronary arterial surgery (1967. 1978). Ann. Surg., 190:444-455, 1979.

6 . COSGROVE, D. M.; LOOP, F. D.; LYTLE, B. W. Predictors of reoperation after myocardial revascularization. J. Thorac. Cardiovasc. Surg., 92:811-821, 1986.

DOBELL, A. R. C. \& JAIN, A. K. - Catastrophic hemmorrhage during redo sternotomy. Ann. Thorac. Surg., 37:273-280, 1984. CARPENTIER, A. - Retrograde cardioplegia through the right atrium. Ann. Thorac, Surg., 41:101-102, 1986.

9 FOSTER, E. D.; FISHER, L. D.; KAISER, G. C.; MYERS, W. O. - Comparison of operative mortality and morbidity for initial and repeat coronary artery bypass grafting: the Coronary Artery Surgery Study-CASS registry experience. Ann. Thorac. Surg., 38:563$570,1984$.

10 GERSH, B. J. \& KRONMAL, R, A, - Coronary arteriography and coronary artery bypass surgery. Morbidity and mortality in patients age 65 years or older: a report from the Coronary Artery Study. Circulation, 67:483-490, 1983

11 GRONDIN, C. M.; POLMAR, J. L.; HEBERT, Y. - Reoperation in patients with patent atherosclerotic coronary vein grafts: a different approach to a different disease. J. Thorac. Cardiovasc. Surg., 87:379$385,1984$.

12 HOFFMANN, R. G.; BLUMLEIN, S. L.; ANDERSON, A. J.; BARBORIAK, J. J.; WALKER, J. A.; RIMM, A. A. - The probability of surviving coronary artery bypass surgery: five years results. JAMA, 243:1341-1344, 1980.

13 JONS, E. L.; CRANER, J. M.; KING III, S. B. - clinical anatomic and functional descriptors influencing morbidity, survival and adequacy of revascularization following coronary bypass. Ann. Surg., 192:390. 402, 1980.

14 KENNEDY, J. W.; KAISER, G. C.; FISCHER, L. D. Clinical angiographic predictors of operative mortality from the Collaborative Study in Coronary Artery Surgery. Circulation, 63:793-802, 1981.

15 KEON, W. J.; HEGGTVEIT, H. A.; LEDEC, J. Perioperative myocardial infarction caused by atheroembolism. J. Thorac. Cardiovasc. Surg., $84: 849-855,1982$.

16 KOSHAL, A.; KEON, W.; BEDARD, P.; BRAIS, M. Indications for and results of, reoperation for coronary disease. Can. J. Surg., 23:173-177, 1980. 
DALLAN, L. A.; OLIVEIRA, S. A.; SOUZA, J. M.; JATENE, M. B.; IGLÉZIAS, J. C. R.; LEMOS, P. C. P.; AULER JÚNIOR, J. O. C.; VERGiNELLI, G.; PILEGGI, F.; JATENE, A. D. - Análise de 1071 reoperaçōes para revascularizaçāo do miocárdio: resultados obtidos e conduta sugerida com base nessa experiência. Rev. Bras. Cir. Cardiovasc. 7(2):61-77, 1992.

17 LOOP, F. D. - Catastrophic hemorrhage during sternal reentry. Ann. Thorac. Surg., 37:271, 1984. (Editorial).

18 LOOP, F. D.; LYTLE, B. W.; COSGROVE, D. M. Influence of the internal mammary-artery graft on 10-year survival and other cardiac events. N. Engl. J. Med., 324:1-6, 1986.

19 LYTLE, B. W.; LOOP, F. D.; COSGROVE, D. M.; TAYLOR, P. C.; GOORMASTIC, M.; PEPER, W.; GILL, C. C.; GOLDING, L. A.; STEWART, R. W. Fifty - hundred coronary reoperations: results and determinants of early and late survival. J. Thorac. Cardiovasc. Surg., 93:847-859, 1987.

20 MARSCHALL Jr., W. G.; SAFFITZ, J.; KOUCHOUKOS, N. T. - Management during reoperation of aortocoronary saphenous vein grafts with minimal atherosclerosis by angiography. Ann. Thorac, Surg., 42:163-167, 1986.

21 NORWOOD, W. I.; COHN, L. H.; COLLINS Jr., J. J. Results of reoperation for recurrent angina pectoris. Ann. Thorac. Surg., 23:9-13, 1977.

OKIES, J. E.; PACIE, U. S.; BIGELOW, J. C. KRAUSE, A. H.; SALOMON, N. W. - Coronary artery surgery: the left internal mammary artery, the graft of choise. Circulation, 70:1213-1221, 1984.

OWEN, Jr. E. W.; SCHOETTLE Jr., G. P.; MAROTTI, A. S.; HARRINGTON, O. B. - The third time coronary artery bypass graft: Is the risk justified? J. Thorac. Cardiovasc. Surg., 100:31-35, 1990.

24 QUAZI, A.; GARCIA, J. A. M.; MISPIRETA, L. A.; CORSO, P. J. - Reoperation for coronary artery disease. Ann. Thorac. Surg., 32:16-22, 1981.

25 REUL, Jr., G. L.; COOLEY, D. A.; OTT, D. A.; COELHO, A.; CHAPA, L.; ETEROVIC, I. - Reoperation for recurrent coronary artery disease: causes, indications, and results in 168 patients. Arch. Surg., 144:1269-1275, 1979.

26 SALOMON, N. W.; PAGE, U. S.; BIGELOW, J. C.; KRAUSE, A. H.; OKIES, J. E.; METZDORFF, M. T. - Reoperative coronary surgery: comparative analysis of 6591 patients undergoing primary bypass and 508 patients undergoing reoperative coronary artery bypass. J. Thorac. Cardiovasc. Surg., 100:250260, 1990.

27 SCHAFF, H. V.; ORZULAK, T. A.; GERSH, B. J.; PIEHLER, J. M.; PUGA, F. J.; DANIELSON, G. K.; PLUTH, J. R. - The morbidity ando mortality of reoperation for coronary artery disease and analysis of late results with use of acturial estimate of eventfree interval. J. Thorac. Cardiovasc. Surg., 85:508$515,1983$.

28 TEMECK, B. K.; KATZ, N. M.; WALLACE, R. B. - An approach to reoperative median sternotomy. J. Cardiac. Surg., 5:14-25, 1990.
29 WALTS, A. E.; FISHBEIN, M. C.; SUSTAITA, H.; MATLOFF, J. M. - Ruptured atheromatous plaques in saphenous vein coronary artery bypass grafts: a mechanism of acute, thrombotic late graft occlusion. Circulation, 65:197-201, 1982.

30 WEISEL, R. D.; HOY, F. B. Y.; BAIRD, R. J. - A comparison of lalternative cardioplegic techniques. $J$. Thorac. Cardiovasc. Surg., 86:97-107, 1983.

\section{Discussāo}

DR. LUIZ FRAGOMENI

Pelotas, RS

Agradeço a gentileza do convite para participar desta apresentação.

A extensa experiência e o excelente resultado aqui apresentados, num assunto de difícil abordagem, enaltecem a cirurgia cardíaca brasileira, além de auxiliar a normatizaçāo do manejo da cardiopatia isquêmica. Por isso, parabenizo o Dr. Dallan e sua equipe pelo brilhantismo do trabalho. No comentário específico desta matéria, julgamos importante a identificação dos fatores de risco que possam alterar a evolução natural após a revascularizaçāo primária do miocárdio. Apesar desses fatores terem sido apontados pelos autores, a utilização de análise paramétrica multivariável quantificaria a influência e as fases em que cada variável estaria ativa. Nesses fatores, os mais importantes: idade jovem, fumo, sexo, hipertensão, hipercolesterolemia, agressividade do processo esclerótico, baixa fração de ejeção ventricular esquerda, anatomia coronariana, não utilização da artéria mamária esquerda e revascularizaçāo incompleta. Observa-se que, nos últimos 2 anos, em 1990 e 1991, o grupo operou um número significativo de pacientes, quando houve importante decréscimo na mortalidade em comparação ao período anterior: $3,49 \%$ versus $10,05 \%$. Dentro de vários fatores, certamente o progresso nos métodos de proteção miocárdica foi fator influente. No período inicial, o pinçamento aórtico intermitente foi utilizado em $59,13 \%$ dos pacientes, em comparação a $26,99 \%$ na segunda fase. Apesar de alguns autores preconizarem sua simplicidade e segurança nos resultados, também sāo cautelosos em não utilizar esta técnica em reoperaçōes, devido à necessidade de clampeamento aórtico múltiplo. $\mathrm{Na}$ aterosclerose aórtica ou na presença de enxertos pérvios, irrigando áreas críticas do miocárdio, o clampeamento parcial da aorta, necessário para anastomoses proximais, certamente incorporará as anastomoses proximais antigas. A manipulaçāo da aorta e do coraçāo que a técnica demanda poderia, também, aumentar o risco de embolização coronariana. Adicionalmente, conforme extensa documentação experimental e clínica, a utilização de 
DALLAN, L. A.; OLIVEIRA, S. A.; SOUZA, J. M.; JATENE, M. B.; IGLÉZIAS, J. C. R.; LEMOS, P. C. P.; AULER JÚNIOR, J. O. C.; VERGINELLI, G.; PILEGGI, F.; JATENE, A. D. - Análise de 1071 reoperaçōes para revascularizaçāo do miocárdio: resultados obtidos e conduta sugerida com base nessa experiência. Rev. Bras. Cir. Cardiovasc. 7(2):61-77, 1992.

técnicas de cardioplegia sangüínea pode reduzir alguma morbidade no miocárdio e o dano isquêmico de reperfusão. Buckberg demonstrou que a absorção de oxigênio pelo miocárdio é reduzida em $90 \%$ no coração em assistolia e descomprimido. $\mathrm{A} 28^{\circ} \mathrm{C}$, nessas condiçōes, a MV02 é de $0,5 \mathrm{ml} / 100 \mathrm{gr} / \mathrm{min}$ e em fibrilação ventricular e na mesma temperatura a MV02 aumenta para $13 \mathrm{ml} / 100 \mathrm{gr} / \mathrm{min}$. O efeito destrutivo de uma inadequada proteção miocárdica pode não se tornar aparente por vários meses ou anos, quando a fibrose miocárdica poderá refletir as cicatrizes de uma proteção ineficiente. Eu gostaria, ainda, de fazer duas perguntas: 1-) Quantos pacientes foram inicialmente endoarterectomizados e qual o comportamento desse grupo? 2-) Qual tem sido a evoluçāo dos enxertos seqüencias com veias e artérias mamárias? Muito obrigado.

\section{DR. RÉGIS JUCÁ \\ Fortaleza, CE}

Queria cumprimentar o Dr. Dallan e seus colegas do InCór e da Beneficência Portuguesa, pela apresentação deste trabalho tão interessante. A primeira pergunta que eu gostaria de fazer é: Qual a diferença técnica em pacientes que têm mamária na $1^{2}$ operação, ou que têm só safena na $1^{2}$ operação? A $2^{a}$ pergunta é: Dr. Dallan, esclareça mais a progressão da doença na artéria nativa e no enxerto. Finalmente: Qual o método que o Dr. Dallan usa para diminuir o sangramento pós-operatório, dado que, em todas as estatísticas, o sangramento é maior na reoperação? Nos últimos 3 anos, nós reoperamos 31 pacientes, sem mortalidade. De vez que não contamos com a aprotimina, temos usado sangue fresco ( 2 unidades), plaquetas e crioprecipitados, o que tende a reverter a maior tendência de sangramento. Queria saber do Dr. Dallan que métodos ele usa visando diminuir o sangramento das reoperaçōes. Parabéns, mais uma vez, por este trabalho excelente.

\section{DR. DALLAN}

\section{(Encerramento)}

Nossos agradecimentos ao Dr. Luiz Fragomeni pela observação criteriosa dos ítens referentes ao nosso trabalho, o que muito nos honra, dada a sua extensa experiência adquirida em Centros internacionais, especialmente em Londres e Minesotta. $O$ Dr. Fragomeni sugeriu a interpretação de nossos resultados em estudo paramétrico multivariado. Recentemente, desenvolvemos essa análise especializada e, nesse sentido, estamos completando um amplo levantamento pertinente às reoperaçōes nas revascularizaçōes do miocárdio, cujos resultados serāo brevemente divulgados. Em relação à realização de endarterectomias nas revascularizaçōes primárias do miocárdio, a nossa impressão é de que esse tipo de procedimento é particularmente desfavorável à reoperação. Como mais de $80 \%$ dos pacientes por nós reoperados foram provenientes de outros serviços, na maioria dos casos não havia a informação exata de detalhes do procedimento primário. O reestudo cinecoronariográfico isolado foi insuficiente para identificar procedimentos tipo endarterectomia na reoperaçăo primitiva, especialmente porque em grande número essas artérias já se encontravam completamente obstruídas. Mas, de qualquer maneira, a re-revascularização de uma artéria já submetida a endarterectomia é bastante difícil. A artéria perde sua anatomia própria e especialmente sua estrutura, 0 que praticamente inviabiliza sua nova abordagem. Da mesma maneira, Dr. Fragomeni, nāo temos dados exatos sobre o número de pacientes externos em que foi realizada ponte seqüencial na revascularização primitiva do miocárdio. Nesses casos, entretanto, ao contrário da endarterectomia, foi possível, pela cinecoronariografia, detectarem-se as artérias que receberam pontes seqüenciais. A imprenssáo que nos ficou, ao analisarmos os 1071 pacientes reoperados, é de que a perviabilidade do enxerto seqüencial foi semelhante à do enxerto isolado. A nova revascularização dessas artérias que receberam ponte seqüencial é plenamente factível, sem que existam grandes problemas adicionais, ao contrário da endarterectomia. Apenas observamos uma dificuldade adicional para identificálas, especialmente quando há grande aderência pleuro-pericárdica. Como uma das maneiras tradicionais para se localizar a artéria coronária já revascularizada é seguir o trajeto da ponte antiga, na presença de ponte seqüencial esse artifício fica prejudicado, o que năo impede, entretanto, uma nova revascularização da artéria em questão. Prof. Regis Jucá: gostaria, também, de agradecer seus comentários elogiosos. Os cuidados de exposiçāo do coração na presença de artéria mamária funcionante diferem, substancialmente, em relação aos enxertos venosos pregressos. Nosso grande temor durante a dissecção da artéria mamária é sua secção inadvertida. Por isso, ainda antes da esternotomia, procuramos avaliar o provável trajeto da artéria mamária e, conseqüentemente, sua distância da tábua posterior do esterno, o que é faciltado pela freqüente presença de clips radiopacos. Mais recentemente, temos posicionado a artéria mamária esquerda através de um orifício no pericárdio, o que previne seu estiramento durante a expansibilidade pulmonar e facilita extremamente as reoperaçōes, uma vez que ela fica posicionada lateralmente (e não anteriormente) ao mediastino. Durante a reoperaçāo, a artéria mamária pregressa poderá ser identificada e cadarçada, o que permite seu pin- 
DALLAN, L. A.; OLIVEIRA, S. A.; SOUZA, J. M.; JATENE, M. B.; IGLÉZIAS, J. C. R.; LEMOS, P. C. P.; AULER JÚNIOR, J. O. C.; VERGINELLI, G.; PILEGGI, F.; JATENE, A. D. - Análise de 1071 reoperaçōes para revascularizaçāo do miocárdio: resultados obtidos e conduta sugerida com base nessa experiência. Rev. Bras. Cir. Cardiovasc. 7(2):61-77, 1992.

çamento durante a cardioplegia. Outra técnica alternativa é não dissecá-la ou tocá-la, prevenindo sua eventual lesão. A desvantagem dessa tática é seu fluxo contínuo, mesmo após o pinçamento aórtico, o que pode atrapalhar as demais anastomoses, dada a presença de circulaçāo colateral. Essa situaçāo poderá ser parcialmente contornada com maior resfriamento do paciente e diminuiçăo do fluxo sistêmico. Os cuidados com os enxertos venosos pregressos têm mudado o resultado das reoperaçōes. Evitando-se a manipulaçāo dos mesmos (especialmente os pérvios e degenerados), até que se oclua a aorta e os desconectem das artérias coronárias, tem-se obtido uma queda acentuada no infarto trans-operatório, conseqüentemente, na morbidade da intervençāo cirúrgica. O Prof. Regis Jucá também nos perguntou da influência da evolução da doença aterosclerótica desses pacientes sobre a reoperaçāo coronária. Nós observamos que a evolução isolada da doença das artérias coronárias foi responsável por cerca de $10 \%$ de nossas reoperaçōes. Por outro lado, atribuímos ao comportamento isolado dos enxertos arteriais $17 \%$ das reoperaçōes. O maior motivo de reoperaçāo, em nossa casuística, decorreu da associaçāo desses dois fatores, que, juntos, somaram cerca de $70 \%$ das causas que levaram à nova revascularizaçăo do miocárdio. O Prof. Regis Jucá comentou o problema referente ao maior sangramento observado nas reoperaçōes e que, na ausência de drogas como a aprotinina, tem contornado essas situaçōes com o uso de sangue fresco, plaquetas e crioprecipitados. Em resposta, devemos considerar que o sangramento constitui motivo de preocupação em qualquer tipo de reoperaçāo. Acreditamos que esse problema seja ainda mais presente em pacientes valvares, nas quais há necessidade de se abrirem cavidades cardíacas para o adequado procedimento. Habitualmente, esse pacientes apresentam estase hepática crônica, normalmente associada a distúrbios de coagulação, o que acarreta ainda maiores problemas durante a hemostasia. O que procuramos fazer nas reoperaçōes é uma abordagem cirúrgica cautelosa. Infelizmente, a premência do tempo não nos permitiu entrar em maiores detalhes durante nossa apresentação, mas, como aspectos técnicos fundamentais, sempre empregamos na esternotomia a serra circular e evitamos a introdução precoce do afastador torácico ortostático. O afastamento das bordas do esterno, antes de se desfazer suas aderências aos tecidos adjacentes, pode levar ao esgarçamento da face anterior do ventrículo direito, ou de outras estruturas, especialmente o átrio direito. O que seria um pequeno problema pode assumir proporçōes catastróficas, caso o cirurgiāo insista em expor o coraçāo e estancar diretamente o sangramento. O que costumamos fazer, diante desse fato, é interromper a dissecção, comprimir o local e entrar em perfusão através de artéria e veia femorais, o que permite esfriar devidamente o paciente e retomar a dissecçāo cardíaca com o coração descomprimido e com possibilidade de repor o sangue perdido. O emprego rotineiro de cell-saver nas reoperaçōes também tem permitido recuperar adequadamente as hemácias desses pacientes, perdidas nessas condiçōes. Quanto à aprotinina, já iniciamos estudo prospectivo e randomizado com a droga, visando avaliar sua atuação na reduçāo do sangramento cirúrgico, e acreditamos que, em futuro bastante próximo, poderemos trazer contribuiçōes a respeito do assunto. Gostaria de encerrar reiterando nossos agradecimentos à comissāo organizadora do Congresso, por mais esta oportunidade de participaçāo. 